\title{
Seleção e alocação de recursos em portfólio de projetos: estudo de caso no setor químico
}

\section{Portfolio of projects: case study of selection and balancing}

\author{
Marisa Padovani ${ }^{1}$ \\ Marly Monteiro de Carvalho' \\ Antonio Rafael Namur Muscat ${ }^{1}$
}

\begin{abstract}
Resumo: Escolher dentre dezenas ou centenas de alternativas, aquelas que deverão compor o portfólio de projetos de uma organização e com qual prioridade, é um problema de decisão multicritério complexo. Este trabalho teve como foco duas etapas críticas da gestão de portfólio: a seleção de projetos e a alocação de recursos. A abordagem metodológica utilizada foi a pesquisa-ação, partindo-se de uma estrutura teórico-conceitual que integra os métodos AHP (Analytic Hierarchy Process) e programação inteira em um modelo híbrido. A pesquisa de campo foi desenvolvida em uma empresa do setor químico, escolhida como unidade de análise, na qual foi implementado o modelo híbrido, de tal forma que os diferentes cenários propostos fossem comparados com o cenário real da organização estudada. Pretendeu-se avaliar a importância e utilidade desse modelo no auxílio à tomada de decisões relacionadas à seleção, priorização e alocação de recursos em projetos. Como principal resultado obtido, verificou-se que o uso do modelo contribui para o alinhamento estratégico, melhora a troca de informações entre os tomadores de decisão da empresa; possibilita a simulação de cenários estratégicos em tempo real e a verificação do impacto na carteira de projetos em execução; prioriza os projetos de forma justificável e estruturada; e permite a alocação de recursos baseada em prioridades.
\end{abstract}

Palavras-chave: Gestão de portfólio de projetos. Seleção e priorização de projetos. Balanceamento do portfólio de projetos. Sistemas de apoio à decisão. AHP.

\begin{abstract}
Among dozens or hundreds of alternatives, choosing those which should make up the projects portfolio of an organization and which priority level is a complex multi-criteria decision matter. This work aims to apply a management model of projects portfolio, using the AHP (Analytic Hierarchy Process) method and an integrated integer program. Another purpose is to validate and evaluate the importance and use of the model to help the decision-making related to the selection, prioritization and balance of projects. Thus, such a model was applied to select and prioritize the projects of a company in the chemical sector, chosen as the unit of analysis. The different scenarios obtained from the decision-making model proposed were compared to the real scenario of the company. Since the author interacted in the company's decision-making not just as an observer, to carry out the study the research-action method was chosen, since it is the most suitable for the case. It could be noticed that the use of the model contributed first, to the strategic alignment of the projects, enabling the exchange of knowledge between the company representatives; secondly, it allows the simulation of strategic scenarios in real time, as well as verifying the impact of the projects portfolio; thirdly, it prioritizes the projects in a justifiable and structural manner through an established mathematical model; finally, it enables to allocate the resources based on priorities.
\end{abstract}

Keywords: Portfolio's management. Selection and prioritization of projects. Decision-making systems. Portfolio's project balance. AHP.

\section{Introdução}

Com a aceleração da globalização dos mercados ocorrida na última década, a concorrência se intensificou no cenário mundial e mais fortemente no âmbito nacional. Para sobreviver, as organizações passaram a estudar alternativas para reduzir seus custos e aumentar a competitividade e por isso,

estão gastando mais tempo em projetos e menos em atividades de rotina (ELTON; ROE, 1998).

Para tratar do problema da gestão do portfólio de projetos e de projetos individuais, uma vasta literatura propõe técnicas de classificação, seleção e priorização, de modo lógico e que facilite a

\footnotetext{
Escola Politécnica, Universidade de São Paulo - USP, Av. Prof. Almeida Prado, 531, Cidade Universitária, CEP 05508-900, São Paulo - SP, Brasil, E-mails: marisa.padovani@poli.usp.br; marly.carvalho@poli.usp.br; armuscat@usp.br

Recebido em 7/9/2010 — Aceito em 25/1/2010
}

Suporte financeiro: Agradecemos ao CNPq e a CAPES pelos suporte ao projeto. 
decisão sobre quais projetos comporão a carteira das organizações e como acompanhar sua evolução no tempo de forma a trazer maior retorno (ARCHER; GHASEMZADEH, 1999; COOPER, R. G.; EDGETT, S. J.; KLEINSCHMIDT, E. J. 1997, 1998, 1999, 2001; GOLDRATT, 1998; GREINER; FOWLER, 2003; JOLLY, 2003; ROUSSEL et al., 1991; SAATY, 1991, 1999). Entretanto, existe uma lacuna na literatura no que se refere à aplicação dessas técnicas na gestão de projetos de investimento das organizações de capital intensivo nacionais, especialmente no setor químico e petroquímico. Para suportar tal afirmação, foram consultadas as bases de dados ISI Web of Science, Scielo e teses e dissertações. Como resultado da pesquisa no ISI Web of Science, utilizando-se como palavras-chave AHP and project, para o tipo de documento Artigo e áreas de interesse Engineering, Operations and Research \& Management Science, Bussiness and Economics and Computer Science, foram encontrados 93 trabalhos para resolver problemas de decisão em diferentes áreas, especialmente, construção civil, tecnologia da informação e setor bancário. Refinando-se a pesquisa, acrescentando-se portfólio à palavra-chave, aparecem 6 artigos, mas nenhum do setor químico. Na base Scielo, em que se encontram periódicos relevantes para a área de Engenharia de Produção no País, são raros os artigos de portfólio, que totalizam 7 artigos, sendo 4 na Gestão e Produção, 3 na Produção e 1 na Pesquisa Operacional. Destes, apenas 4 são artigos de portfólio de projetos e nenhum deles com foco na indústria química. Hsuan e Hansen, (2007) e Miguel (2008) tratam de portfólio no desenvolvimento de produtos, Moraes e Laurindo (2003), de portfólio de projetos de Tecnologia da Informação (TI) e Rabechini Junior et al. (2005) focam em empresas prestadoras de serviço de interconexão eletrônica.

Assim, visando contribuir com o conhecimento dos processos de decisão em portfólio de projetos na área química, especialmente no que se refere às práticas de seleção e priorização de projetos, este trabalho propõe examinar a aplicação de um método híbrido baseado no AHP e na programação inteira. O método híbrido é aplicado em uma empresa nacional, de capital intensivo do setor químico e petroquímico, de maneira que aspectos quantitativos (como, retorno sobre o investimento, produtividade, cumprimento de prazos e orçamentos) e qualitativos (riscos ambientais, satisfação do cliente, aspectos de segurança, interesses da comunidade ou questões políticas, etc.) estejam presentes.

\section{Objetivos da pesquisa}

Esta pesquisa tem como objetivos gerais compreender o problema da seleção e priorização de projetos e alocar recursos em ambientes em que concorram muitos projetos de categorias distintas, pela aplicação e verificação do método proposto nas tomadas de decisões da área de projetos da empresa escolhida como unidade de análise. Além disso, pretende-se estudar o grau de alinhamento estratégico dos projetos com o negócio; que permita despertar o espírito crítico relacionado ao processo decisório e à gestão de portfólio de projetos. O objetivo específico da pesquisa é definir o melhor conjunto de projetos para a organização, considerando-se que exista restrição de recursos do orçamento anual de investimentos e tais recursos devem ser aplicados de forma balanceada na organização, considerando-se as categorias de projetos e as diferentes unidades industriais. $\mathrm{O}$ foco deste estudo se concentra no nível de planejamento estratégico da organização. Neste nível, são tomadas decisões para gestão da capacidade de produção, visando garantir o crescimento da companhia à longo prazo e manter a continuidade e excelência de suas operações à curto prazo.

\section{Fundamentos teóricos}

O processo de gestão de portfólio de projetos envolve diferentes etapas de decisão, para que projetos que agreguem valor às organizações sejam selecionados e priorizados. Neste sentido, o prêmio Nobel de Economia em 1978, Simon (1960), afirma que o processo de tomada de decisão é sinônimo de prática de gestão e envolve questões básicas sobre o que deve ser feito, quando, como, onde e por quem. Outras funções gerenciais como organizar, implementar e controlar, estão correlacionadas fortemente com a tomada de decisão.

Com o objetivo de melhorar a qualidade da tomada de decisões, diversos estudos têm sido desenvolvidos na área de processo decisório. São exemplos desses estudos os trabalhos de HAMMOND, J. S.; KEENEY, R. L.; RAIFFA, H. (1998), que trata das armadilhas no processo de decisão e como evitá-las; os trabalhos de Nutt (1992), Garvin (2001) e Kaufmann (1975), que abordam as questões políticas e os jogos de poder existentes no processo de tomada de decisão; Samson (1980), Clemen (1991) e Garber (2002), que descrevem os passos do processo de tomada de decisões e Saaty (1991), que propõe o uso do método AHP (Analytic Hierarchy Process) como ferramenta para a tomada de decisão na seleção e priorização de projetos de um portfólio.

Outros estudos tratam a questão do alinhamento entre a tomada de decisões nas organizações e sua estratégia. Segundo estes trabalhos, os gestores de uma organização devem conhecer sua estratégia, quais as formas que ela utiliza para competir, quem são seus stakeholders, saber identificar possíveis trade-offs e quais são suas competências essenciais (LUEHRMAN, 1998; CARVALHO; 
LAURINDO, 2003; BOLDWIJN; KUMPE,1990; PRAHALAD; HAMEL, 1990; BANERJEE, 2003; SLACK, 1993 e 1998).

No que se refere à implementação da gestão de portfólio, Brown e Eisenhardt (1998) e Eisenhardt e Brown (2000) afirmam que a tomada de decisões não é uma tarefa trivial; pois engloba incertezas de mercado e tecnológicas; negociação por recursos quase sempre escassos entre diferentes áreas da companhia e constantes mudanças devido à turbulência do mercado. Além disso, dificuldades decorrentes da natureza dinâmica da gestão de portfólio constituem-se num processo contínuo que demanda engajamento no processo de tomada de decisão, com fluxo bem definido e pontos de verificação pré-estabelecidos.

Neste trabalho, é utilizado o conceito de gestão de portfólio proposto por Cooper, Edgett, Kleinschmidt (1999):

Um processo de decisão dinâmico, por meio do qual uma lista com os projetos é constantemente atualizada e revisada. Neste processo, novos projetos são avaliados, selecionados e priorizados; projetos existentes podem ser acelerados, eliminados ou ter sua prioridade reduzida, sendo os recursos alocados e realocados para os projetos ativos. O processo de decisão do portfólio é caracterizado pela incerteza e mudanças das informações, oportunidades dinâmicas, múltiplas metas e considerações estratégicas, interdependência entre projetos e múltiplas tomadas de decisões e locais.

Para estes autores, gestão de portfólio é a manifestação da estratégia do negócio, que estabelece onde e como o investimento será feito no futuro.

Archer e Ghasemzadeh (1999) analisaram vários métodos de gestão de portfólio e concluíram que os mais apropriados pressupõem atividade de seleção periódica das propostas de projetos disponíveis e reavaliação dos projetos existentes e em fase de execução, possibilitando o atendimento aos objetivos estratégicos da empresa, sem exceder recursos disponíveis ou violar outras restrições do negócio, atendendo aos requisitos mínimos da organização, tais como: lucratividade potencial, aceitabilidade potencial, montante de investimentos e outros. Estes autores observam que a gestão de portfólio é uma atividade muito importante na rotina das organizações. Entretanto, há muitas técnicas, algumas das quais divergentes e outras não aplicáveis devido à sua complexidade. Para contribuir com a simplificação dos processos de gestão de portfólio, os autores consideram o uso de um modelo integrado para a seleção do portfólio de projetos, em que há uma fase de seleção dos projetos, uma fase de ajuste e uma fase de otimização, sendo, esta última fase, assistida por um modelo de Programação Linear. No estágio de seleção do portfólio, são recomendadas as técnicas AHP, Q-Sort ou comparação por pares (pairwise comparison).
Cooper, Edgett, Kleinschmidt (1999) estudaram o processo de gestão do portfólio de projetos e sua implementação em diferentes empresas e encontraram uma gama dos mais diversos métodos, como listado a seguir: métodos financeiros (77,3\%); métodos de estratégia do negócio $(64,8 \%)$; diagramas de bolhas (40,6\%); scoring models (37,9\%); e checklists (20,9\%). Como este levantamento sugere, as empresas utilizam múltiplos métodos de gestão de portfólio, sendo os métodos financeiros os mais utilizados (COOPER, R.; EDGETT, S.; KLEINSCHMIDT, E., 2001). Desta forma, a empresa deve ser capaz de escolher o melhor conjunto de métodos disponíveis para sua gestão de portfólio (MCFARLAN, 1981).

Adner e Levinthal (2001); Roussel, Saad, Erickson (1991); Cooper, Edgett, Kleinschmidt (1997, 1998, 1999, 2001); Tritle, Scriven, Fusfeld (2000); Wheelwright; Clark (1992); Archer e Ghasemzadeh (1999) destacam a importância de se conseguir um equilíbrio entre os projetos do portfólio em vários aspectos tais como: balanceamento entre projetos revolucionários e incrementais; balanceamento entre inovação de produto e inovação de processo; balanceamento entre risco e oportunidade; e balanceamento entre curto prazo e longo prazo.

Greiner e Fowler (2003) apresentam uma aplicação de um modelo semelhante ao proposto por Archer e Ghasemzadeh (1999) para o monitoramento e seleção de projetos para o Departamento de Defesa Norte-Americano, pertencente à força área daquele país. Na fase de otimização, Greiner e Fowler (2003) utilizaram a Programação Inteira combinada com diferentes heurísticas. Os autores concluíram que houve melhoria substancial no valor do portfólio, que a definição da hierarquia e comparação entre critérios no método AHP é rápida e que a técnica é útil em ambientes que exijam avaliações de aspectos qualitativos e quantitativos.

O processo de análise hierárquica é uma técnica de análise de decisão desenvolvida por Saaty em 1970 para resolver problemas de decisão multicritério, nos quais o tomador de decisão deve fazer uma escolha entre várias alternativas. O método tem como objetivo simular a maneira como as pessoas pensam. O AHP é uma ferramenta que auxilia a priorização e a decisão no caso em que há presença de fatores qualitativos e quantitativos. Este método permite análise e síntese de problemas complexos, justificando decisões e avaliações complicadas e tornando possível examinar os elementos ou partes de um problema de forma isolada (FORMAN; SELLY, 2001). Cada elemento é comparado com outro, sempre segundo um dos critérios, aos pares. Greiner e Fowler (2003) apresentam como passos para o desenvolvimento do método: 1) Definir o problema; 2) Definir o objetivo; 3) Listar as alternativas de solução e critérios (e/ou subcritérios) pelos quais as alternativas de solução 
serão avaliadas; 4) Organizar as definições anteriores em uma hierarquia na qual o primeiro nível é o objetivo, o segundo é composto pelos critérios que podem ser subdivididos nos níveis subsequentes, sendo o último nível destinado às alternativas; 5) Comparar cada elemento do mesmo nível entre si tendo em vista o nível superior; 6) Determinar os vetores de priorização de cada nível e obter do vetor de priorização as alternativas de solução. Este vetor indicará qual alternativa é a melhor.

Greiner e Fowler (2003) destacam que a utilização do AHP sozinho não permite analisar o portfólio de projetos em relação às restrições de recursos. Portanto, o vetor de priorização das alternativas de solução obtido com o AHP funciona como entrada para a seleção de projetos (Pi na formulação abaixo). Os parâmetros do vetor achado pelo AHP servem para dar a importância/valor de cada projeto na formulação matemática. Assim, o objetivo da programação inteira é de maximizar o valor da carteira, respeitando sempre a restrição. A formulação proposta no artigo é apresentada na Equação 1.

Resultado do AHP

$$
\begin{array}{ll}
\text { MAX } & V=\sum_{i \in N} P_{i} * X_{i} \\
\text { Restrição } & \sum_{i \in N} C_{i} * X_{i} \leq B \quad \text { Orçamento } \\
& X_{i} \in\{0,1\}
\end{array}
$$

Variável de decisão : igual a 1 se o

projeto for escolhido e 0 caso contrário.

Este trabalho foca as etapas de seleção e alocação de recursos, no contexto da Gestão de Portfólio de Projetos, cuja estrutura teórico-conceitual é baseada nos artigos de Archer e Ghasemzadeh (1999) e Greiner e Fowler (2003), conforme detalhado nas seções seguintes deste artigo.

\section{Metodologia}

Como o tema de Gestão de Portfólio em Projetos é ainda emergente em empresas brasileiras, optou-se pela abordagem metodológica da pesquisa-ação, que foi desenvolvida em uma empresa do setor químico e petroquímico nacional.

\section{A pesquisa-ação é}

um tipo de pesquisa social com base empírica que é concebida e realizada em estreita associação com uma ação ou com a resolução de um problema coletivo e no qual, pesquisadores e participantes, representativos da situação ou do problema, estão envolvidos de modo cooperativo ou participativo (THIOLLENT, 2004).
Segundo Bryman (1989), para realizar a pesquisaação, o investigador precisa envolver-se diretamente com a organização estudada, o que a diferencia do método de estudo de caso.

São objetivos da pesquisa-ação contribuir para o melhor equacionamento possível do problema central na pesquisa e obter informações que seriam de difícil acesso por meio de outros procedimentos, aumentando nosso conhecimento de determinadas situações, permitindo generalizações.

Este trabalho foi iniciado em 2005, seguindo o ciclo de vida da pesquisa-ação proposto por Coughlan e Coghlan (2002). A Figura 1 apresenta uma síntese da abordagem metodológica adotada na presente pesquisa, mesclando o quadro teórico apresentado na seção 3 deste artigo, em especial as contribuições de Archer e Ghasemzadeh (1999) e de Greiner e Fowler (2003), e o ciclo da metodologia de pesquisa-ação.

O primeiro passo do trabalho foi a realização de uma pesquisa bibliográfica preliminar, sobre os temas: gestão de portfólio de projetos, princípios da análise de decisão, estratégia e tomada de decisões, com o objetivo de conhecer os principais problemas de decisão na área de gestão de portfólio, quais as tratativas que têm sido dadas a tais problemas e qual a relação entre estratégia nas organizações e a gestão de portfólio de projetos. A avaliação dessa bibliografia tornou possível a delimitação do problema a ser estudado. Com o avanço do trabalho, a revisão bibliográfica foi complementada com textos sobre teoria dos stakeholders e dos trade-offs, pois se percebeu que o processo de tomada de decisão é influenciado pelos stakeholders, que fazem parte do processo decisório em cada etapa do ciclo de vida da organização e que tais decisões envolvem trade-offs, que precisam ser conhecidos e avaliados para que a decisão tomada seja a mais adequada.

$\mathrm{Na}$ organização selecionada para a pesquisa de campo, duas fontes de pesquisas principais foram utilizadas para a coleta de dados: consulta aos bancos de dados de sistemas de gestão de projetos e investimentos da organização e consulta a documentos da empresa. Cerca de 1000 projetos realizados no período de 2001 a 2005 foram analisados.

Os dados coletados foram utilizados para se fazer a caracterização do portfólio de projetos da empresa. Como complemento à análise dos dados coletados, foram realizadas entrevistas com os gestores de projetos das áreas de pesquisa e desenvolvimento $(\mathrm{P} \& \mathrm{D})$ e de projetos de engenharia, pessoas-chave no processo de gestão do portfólio da organização. Nestas entrevistas, foram utilizados como ferramentas de apoio questionários não estruturados e reuniões de brainstorming. Na sequência, foi realizado um diagnóstico do gerenciamento de portfólio da organização objeto de análise, de modo a se obter uma fotografia da situação atual e analisou-se o referido 
processo, confrontando-o com o processo proposto por Archer e Ghasemzadeh (1999), identificando-se lacunas entre a teoria e prática. Como último passo da pesquisa, foi aplicado um modelo que utiliza os métodos AHP e Programação Inteira integrados para a seleção e priorização dos projetos da empresa. Também foram empregadas algumas heurísticas para agregar as restrições ao modelo. Os principais resultados do diagnóstico realizado foram apresentados em Padovani, Carvalho, Muscat (2006).

São foco deste estudo as etapas finais do ciclo de pesquisa-ação, apresentadas na Figura 1, que correspondem ao planejamento da ação, à implementação e à avaliação dos resultados em que foram realizadas as atividades de aplicação do método híbrido.

A utilização de fontes diferentes de informações via bancos de dados, reuniões de grupo e entrevistas individuais tornaram as informações confiáveis e permitiram a validação do método aplicado, estando de acordo com as recomendações de Thiollent (2004).

\section{A pesquisa de campo: caracterização e diagnóstico dos projetos}

A empresa alvo deste estudo, denominada doravante de "Alfa" é nacional, privada e de capital intensivo, pertencente aos segmentos químico e petroquímico, com sede em São Paulo. Trata-se de uma empresa de grande porte, com atuação no mercado interno e externo, dispondo de 7 unidades industriais no
Brasil e 3 no exterior. Seu faturamento total supera 1,5 bilhões de reais/ano, sendo alocados em pesquisa e desenvolvimento cerca de $2 \%$ de sua receita anual. Do total de aproximadamente 1200 funcionários no Brasil, $12 \%$ pertencem às áreas de pesquisa e desenvolvimento (P\&D) e engenharia (Projetos). Além das unidades industriais, a empresa dispõe de um moderno centro de pesquisas.

Anualmente, pouco antes do período orçamentário, a empresa Alfa realiza com seus executivos reuniões para elaboração de seu "Plano Estratégico", documento que descreve a visão do mercado, linhas de produtos e processos que serão necessários no horizonte dos 3 anos subsequentes. Encerrada a fase de planejamento estratégico, cada área, baseada no "Plano Estratégico", elabora seus planos de ação e respectivos orçamentos para o próximo ano. As propostas de investimento e despesas são encaminhadas para a diretoria que as analisa e aprova ou rejeita, segundo critérios pré-estabelecidos pela direção da organização.

São várias as entradas de novos projetos candidatos a compor o portfólio da organização em estudo: 1) Vendas, que durante as visitas periódicas aos clientes identifica seus anseios e necessidades; 2) Clientes-chave, que semanas antes do início do período de planejamento estratégico são convidados a visitar a organização e fazer apresentações sobre seus novos negócios, perspectivas do mercado em que atuam e projeções de vendas ligadas às linhas de produtos fornecidas pela empresa Alfa; 3) Marketing, por meio de pesquisas de mercado bienais; e 4) Área de novos negócios, pelo estudo de patentes e tecnologias

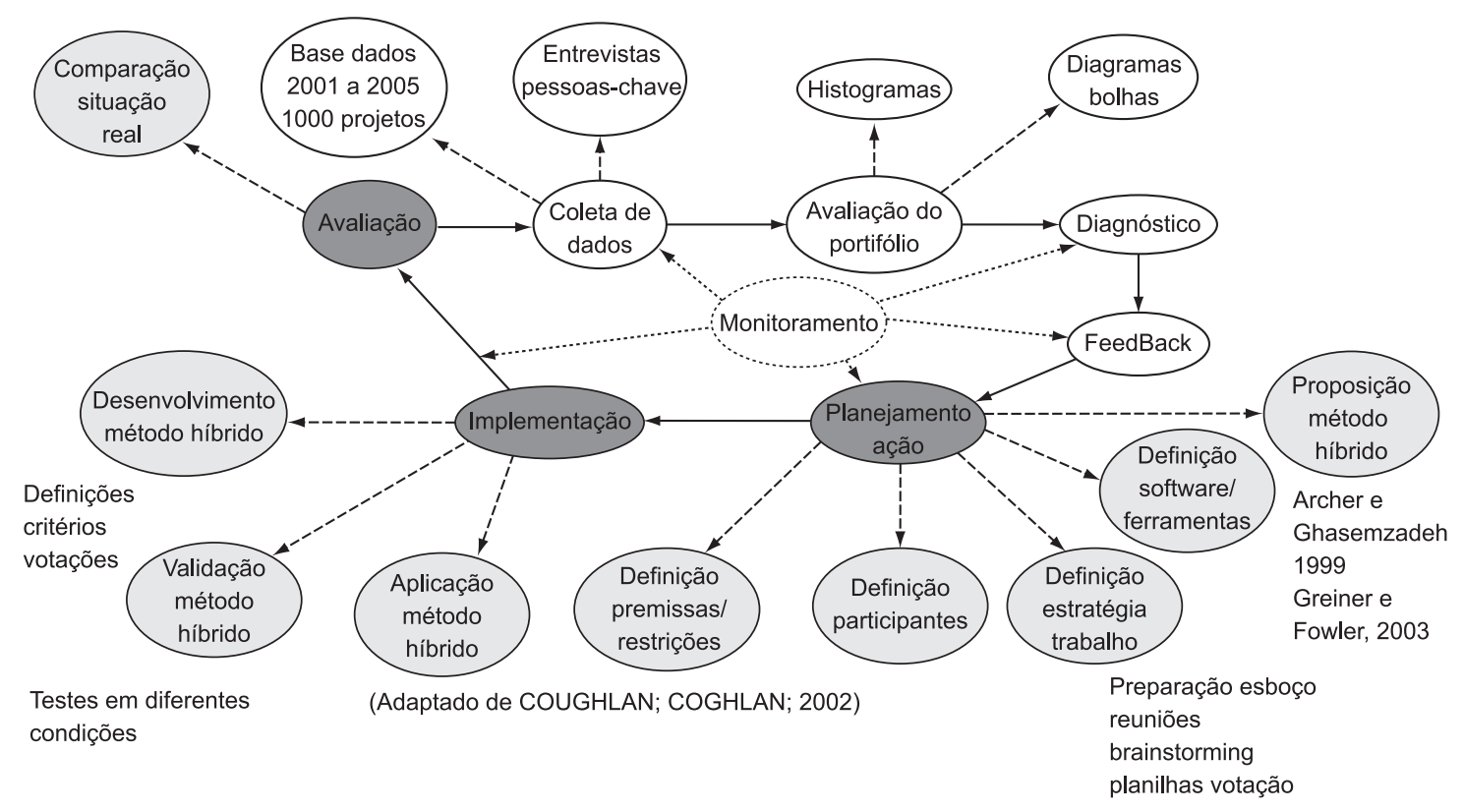

Figura 1. Ciclos de Pesquisa-Ação para a pesquisa de campo. 
ou possíveis aquisições. Essas demandas acabam gerando necessidades de adequação das instalações, se desdobrando em solicitações de atendimento a requisitos de aumento de capacidade, construção de novas instalações, adequação a demandas ambientais, de segurança, infraestrutura de TI e manutenção industrial, que compõem o portfólio de projetos da organização.

Tais projetos são classificados da seguinte forma: Projetos com investimento e Projetos sem investimento. No primeiro caso, com investimento, os projetos têm subclassificações por natureza do investimento (estratégicos ou operacionais), tipo (aquisições, substituição/reparos e construção de novas instalações) e característica (aumento de capacidade, novos produtos, administrativos, redução de custos, controle ambiental, segurança, informática, qualidade, fim de vida útil e modernização). No segundo caso, sem investimento, os projetos podem ser de $\mathrm{P} \& \mathrm{D}$, divididos por tipo de atividade (projetos de produtos, serviços técnicos e assistência técnica), complexidade (tipo I a IV, especial e catalisadores) e negócio/segmento (intermediários de síntese, tensoativos, solventes e outros produtos de performance) ou se tratar de estudos de outras áreas.

A empresa Alfa utiliza critérios de seleção de projetos conforme proposto por McFarlan (1981) quanto ao tamanho e conhecimento da tecnologia, sendo grande parte relacionada com oportunidades de otimização e transferência de tecnologia, a maioria de baixo risco. Parte significativa do portfólio de pesquisa, desenvolvimento e engenharia (PD\&E) concentrava-se em mercados nos quais a empresa tinha baixa capacidade de competir ou em negócios em que não valia a pena investir.

Considerando-se o período de coleta de dados adotado na pesquisa, observou-se que a gestão e a seleção dos projetos de PD\&E, projetos sem investimento, apresentavam enfoque estratégico inadequado, faltavam diretrizes claras e a demanda por serviços técnicos e por projetos não tinha foco, nem controle. Essa situação gerava perturbações na etapa de implantação de projetos, sendo uma das causas do grande número de projetos de engenharia e de constantes mudanças de escopo. O fato da empresa não ter uma estratégia clara de desenvolvimento acabava por influenciar suas decisões quanto ao grau de especialização necessário, política de canal, qualidade de produto, liderança tecnológica e integração vertical. Para resolver o problema de falta de foco, Prahalad e Hamel (1990) sugerem que as organizações criem um comitê de gerentes de alto escalão para identificar, cultivar e monitorar o desenvolvimento de produtos e competências essenciais à organização. As ações propostas pela literatura não foram observadas na empresa Alfa durante a etapa de coleta de dados deste trabalho.
Por outro lado, a gestão dos projetos selecionados com investimento aprovado era feita por dois critérios básicos: o financeiro e o estratégico, confirmando as observações de Cooper, Edgett, Kleinschmidt (2001) de que as empresas utilizam múltiplos métodos, sendo o financeiro o mais empregado. Neste caso, observou-se, para os dados coletados, a ausência de regras de priorização para os projetos do portfólio; tendo, como consequência, frequentes alterações de escopo, atrasos no cronograma, estouros de orçamentos e problemas de qualidade pós-implantação. Todos esses problemas são citados pela literatura por McFarlan (1991), Elton e Roe (1998) e Goldratt (1998), entre outros e foram constatados na prática.

\section{Método híbrido para seleção de projetos e alocação de recursos}

Considerando-se os resultados da etapa de caracterização e diagnóstico do portfólio estudado, propôs-se a aplicação e validação de um modelo de gestão de portfólio de projetos para a empresa Alfa com o intuito de verificar sua adequação, utilidade e eficácia, permitindo a redução do número de projetos com e sem investimentos aprovados com consequente redução na complexidade da gestão do portfólio. Assim, a tomada de decisão passaria a ocorrer de maneira estruturada, segundo critérios lógicos, pré-estabelecidos, e permitindo, ainda, $\mathrm{o}$ atendimento aos anseios dos stakeholders da organização nas diferentes fases do seu ciclo de vida. O modelo deveria, também, permitir a obtenção de um portfólio de projetos alinhado com a estratégia da empresa e balanceado quanto aos aspectos de maturidade da tecnologia, grau de inovação e perfil de investimentos, conforme recomendação da literatura acadêmica consultada.

Como ferramenta para auxiliar a organização a selecionar seus projetos de acordo com sua estratégia, propôs-se neste trabalho adaptar os modelos sugeridos por Archer e Ghasemzadeh (1999) e Greiner e Fowler (2003). Para que isso fosse possível, foram fundamentais as etapas de definição dos critérios de seleção de projetos pela organização e a identificação das restrições, para que fossem incorporadas ao modelo, permitindo a simulação de cenários. Também foi introduzido no modelo um comitê executivo, conforme proposto por Prahalad e Hamel (1990), com a função de tomar as decisões no filtro inicial de pré-seleção dos projetos e a Diretoria da Organização com a função de tomar as decisões no filtro dos projetos que necessitam de investimentos.

A Figura 2 apresenta o modelo estrutural para a seleção e priorização de projetos, adotado neste trabalho. Existem dois marcos para análise do portfólio: um pré-filtro inicial, para selecionar as ideias tecnicamente viáveis, de acordo com critérios 
previamente definidos pela equipe de gestores que participou das reuniões de elaboração deste trabalho; e um segundo filtro, na etapa de aprovação de investimentos, para avaliar, segundo os critérios financeiros e objetivos estratégicos da organização, se tais projetos são viáveis e se é recomendado investir. Após o segundo filtro, o modelo apresentado na Figura 2 utiliza um otimizador no qual são aplicadas restrições aos projetos para permitir que a empresa escolha o melhor portfólio de projetos, do ponto de vista da utilização do orçamento aprovado.

Ao iniciar a atividade de desenhar a hierarquia de projetos utilizando o método AHP, observou-se que não era possível estabelecer critérios únicos para todos os tipos de projetos existentes, segundo a classificação adotada pela organização estudada, que era dúbia e induzia ao erro, principalmente ao definir o que era fim de vida útil, modernização, aumento de capacidade ou redução de custos (seção 5). Como o método AHP pressupõe a comparação por pares entre critérios, subcritérios e projetos, era fundamental organizar os projetos de tal forma que eles pudessem ser comparados. Por isso foi necessária reclassificação dos projetos segundo a similaridade dos critérios de decisão utilizados, o nível estratégico dos tomadores de decisão envolvidos em cada categoria de projetos e as unidades de negócio envolvidas. A reclassificação dos projetos também permitiu a identificação de distorções existentes na primeira análise. A necessidade de reclassificação dos projetos confirma as observações de McFarlan (1981) de que é necessário classificar os projetos de modo que seja possível diferenciá-los e compará-los com projetos similares.

O Quadro 1 apresenta o relacionamento entre a classificação de projetos com investimento aprovado adotada pela organização e a nova classificação proposta.

Uma vez concluída a fase de reclassificação e análise dos projetos da organização, foi realizada uma atividade de feedback, com apresentação da nova classificação para os gestores da empresa, bem como as novas conclusões dela decorrentes, conforme previsto no ciclo de pesquisa-ação mostrado na Figura 1.

A partir deste ponto, o trabalho retornou à etapa de aplicação/validação do modelo híbrido, denominada, parametrização do software. O software escolhido para a realização deste trabalho foi o Decision Lens versão 1.6.16, desenvolvido pelo Dr. Thomas Saaty da Wharton School of Business.

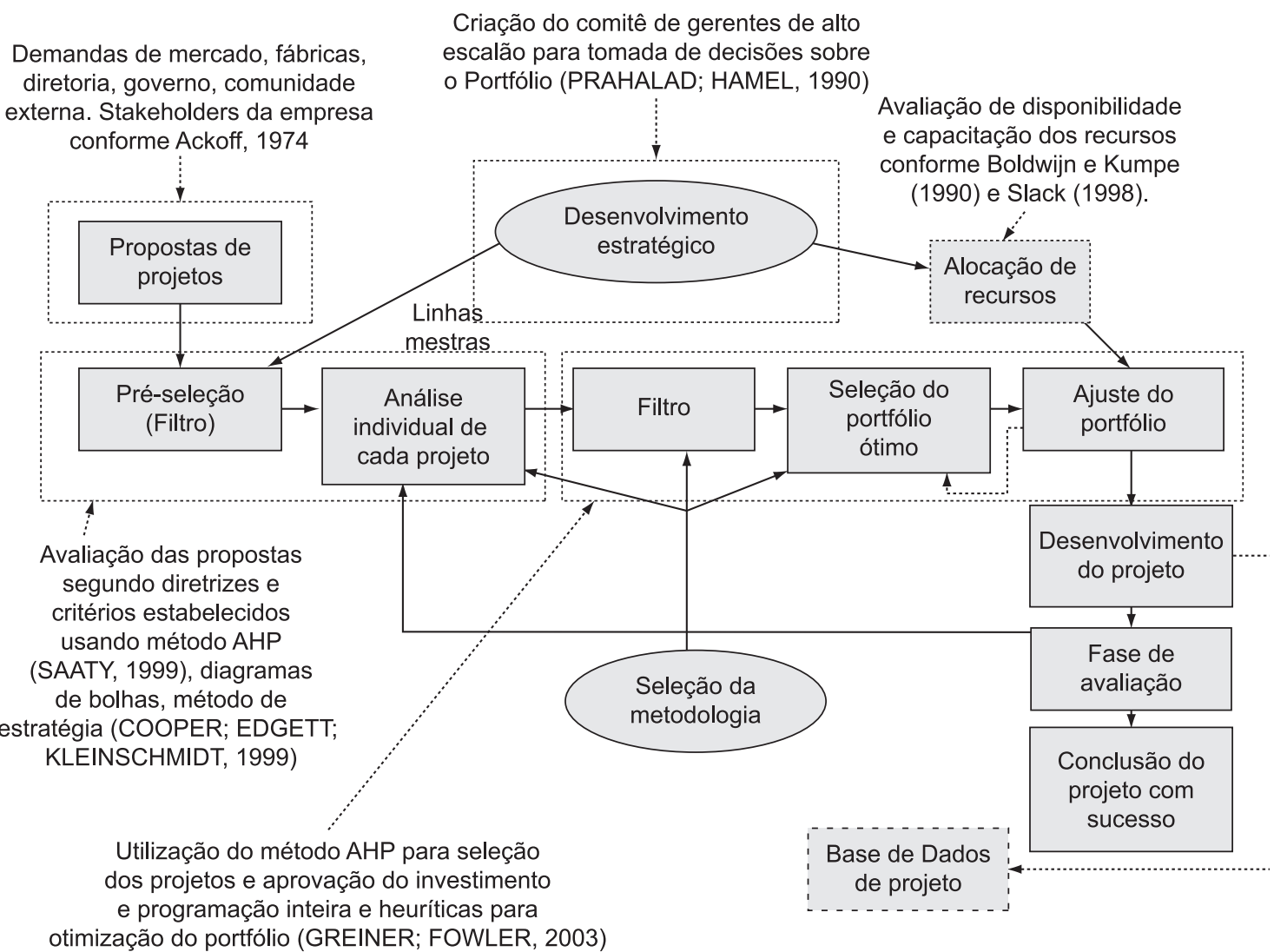

Figura 2. Modelo de seleção e priorização de projetos adaptado de Archer e Ghasemzadeh (1999). 
A parametrização foi feita pela definição dos objetivos, identificação de critérios e subcritérios, seleção das alternativas de projetos, definição dos participantes, construção da estrutura de decisões e votação de pesos dos critérios e escala de variação dos critérios (ratings), além do cadastro dessas informações no software adotado como ferramenta de trabalho. O passo seguinte foi a definição das restrições e relações de dependências entre os projetos. Por último, foi feita a votação dos projetos para a definição das prioridades com o AHP e o refinamento da priorização por meio do uso das restrições e dependências previamente definidas. Uma ilustração da sequência de atividades executadas nesta etapa é apresentada pela Figura 3.

As fases do modelo foram executadas 6 vezes, com diferentes comitês de stakeholders segundo a categoria dos projetos, pois a reclassificação dos projetos nos levou à necessidade de criar 6 estruturas de decisão. A técnica de decomposição do problema em modelos de estrutura, bem como todos os passos do processo de decisão descritos por Clemen (1991) foram empregados nesta etapa do trabalho. Destaca-se que, embora os comitês decisórios fossem distintos com autonomia para definir critérios e votar os projetos em que estavam habilitados, a hierarquia da decisão é integrada e articulada por meio do modelo híbrido (Figura 4).

Para que a avaliação da diretoria esteja alinhada com a estratégia da organização, foi concebida uma estrutura principal, à qual as 4 estruturas das categorias de projetos - manutenção, TI, engenharia e Infraestrutura de P\&D - são subordinadas, conforme ilustra a Figura 4. $\mathrm{Na}$ estrutura principal, o grau de contribuição das

Quadro 1. Relacionamento entre classificação de projetos da empresa e proposta pelos autores.

\begin{tabular}{|c|c|c|c|}
\hline $\begin{array}{l}\text { Classificação } \\
\text { proposta }\end{array}$ & $\begin{array}{l}\text { Classificação } \\
\text { da empresa }\end{array}$ & Descrição & $\begin{array}{l}\text { Local de } \\
\text { aplicação }\end{array}$ \\
\hline \multirow[t]{5}{*}{$\begin{array}{l}\text { Projetos de } \\
\text { manutenção }\end{array}$} & $\begin{array}{l}\text { VU - fim } \\
\text { de vida útil }\end{array}$ & $\begin{array}{l}\text { Investimentos que visam a substituição de um bem devido a } \\
\text { exaustão ou obsolescência }\end{array}$ & $\begin{array}{l}\text { Instalação } \\
\text { industrial }\end{array}$ \\
\hline & $\begin{array}{l}\mathrm{CA}-\text { controle } \\
\text { ambiental }\end{array}$ & $\begin{array}{l}\text { Investimentos cuja implantação visa atendimento de requisitos } \\
\text { de proteção ambiental }\end{array}$ & $\begin{array}{l}\text { Instalação } \\
\text { industrial }\end{array}$ \\
\hline & $\begin{array}{l}\mathrm{SG} \text { - segurança } \\
\text { industrial }\end{array}$ & $\begin{array}{l}\text { Investimentos que visam garantir a segurança operacional e } \\
\text { resguardar o patrimônio instalado }\end{array}$ & $\begin{array}{l}\text { Instalação } \\
\text { industrial }\end{array}$ \\
\hline & $\begin{array}{l}\text { MD - } \\
\text { modernização }\end{array}$ & $\begin{array}{l}\text { Investimentos que visam automatizar e incorporar às instalações } \\
\text { novas tecnologias para aumento de produtividade, segurança, } \\
\text { qualidade ou redução de custos }\end{array}$ & $\begin{array}{l}\text { Instalação } \\
\text { industrial }\end{array}$ \\
\hline & $\begin{array}{l}\mathrm{RC}-\text { redução } \\
\text { de custos }\end{array}$ & $\begin{array}{l}\text { Investimentos cujo objetivo principal seja reduzir os custos de } \\
\text { produção }\end{array}$ & $\begin{array}{l}\text { Instalação } \\
\text { industrial }\end{array}$ \\
\hline \multirow{2}{*}{$\begin{array}{l}\text { Projetos de } \\
\text { infraestrutura } \\
\text { de P\&D }\end{array}$} & QS - qualidade & Investimentos em melhoria da qualidade de produtos & $\begin{array}{l}\text { Laboratórios } \\
\text { de P\&D }\end{array}$ \\
\hline & $\begin{array}{l}\text { VU - fim } \\
\text { de vida útil }\end{array}$ & $\begin{array}{l}\text { Investimentos que visam a substituição de um bem devido a } \\
\text { exaustão ou obsolescência, inclui reforma sdas instalações }\end{array}$ & $\begin{array}{l}\text { Laboratórios } \\
\text { de P\&D }\end{array}$ \\
\hline \multirow[t]{3}{*}{$\begin{array}{l}\text { Projetos de } \\
\text { informática }\end{array}$} & $\begin{array}{l}\text { IF - } \\
\text { informática }\end{array}$ & $\begin{array}{l}\text { Investimentos em software, hardware e outros ativos de } \\
\text { informática }\end{array}$ & $\begin{array}{l}\text { Instalação } \\
\text { industrial }\end{array}$ \\
\hline & & & $\begin{array}{l}\text { Instalações de } \\
P \& D\end{array}$ \\
\hline & & & $\begin{array}{l}\text { Instalações } \\
\text { administrativas }\end{array}$ \\
\hline \multirow[t]{3}{*}{$\begin{array}{l}\text { Projetos de } \\
\text { engenharia }\end{array}$} & $\begin{array}{l}\mathrm{CP} \text { - aumento } \\
\text { de capacidade }\end{array}$ & Projetos de amliações de capacidade da linha de produtos atual & $\begin{array}{l}\text { Instalação } \\
\text { industrial }\end{array}$ \\
\hline & $\begin{array}{l}\mathrm{NP}-\text { novos } \\
\text { produtos }\end{array}$ & Investimentos que visam o lançamento de novos produtos & $\begin{array}{l}\text { Instalação } \\
\text { industrial }\end{array}$ \\
\hline & $\begin{array}{l}\text { EE - estudos } \\
\text { estratégicos }\end{array}$ & $\begin{array}{l}\text { Investimentos destinados à execução de estudos de viabilidade de } \\
\text { novos negócios e que serão contabilizados como ativo diferido } \\
\text { (inclui aquisição de novas empresas, participações minoritárias, } \\
\text { joint ventures/parcerias, venda de tecnologia). }\end{array}$ & $\begin{array}{l}\text { Instalação } \\
\text { industrial }\end{array}$ \\
\hline
\end{tabular}


4 estruturas a ela subordinadas com os 2 objetivos estratégicos da empresa, excelência e crescimento, constituem-se nos critérios de decisão. É o vínculo da estrutura principal com as estruturas das 4 categorias de projeto que garantem o alinhamento entre os projetos do portfólio e a estratégia, bem como define de acordo com esse alinhamento o montante de investimentos que será destinado a cada classe de projetos.

Exceção foi a estrutura de decisão criada para as propostas de projetos de $\mathrm{P} \& \mathrm{D}$, apresentada pela
Figura 5, que é independente das demais, pois não concorre pelos recursos orçamentários com as demais categorias e tem a função do pré-filtro (Figura 2). Esse pré-filtro será utilizado pelo comitê executivo da empresa para avaliar se novas propostas de projetos de P\&D devem ou não passar a compor o portfólio da organização e se projetos existentes devem ser mantidos ou paralisados.

Para a construção de todas as estruturas de decisão, optou-se pela elaboração de um esboço, para posterior

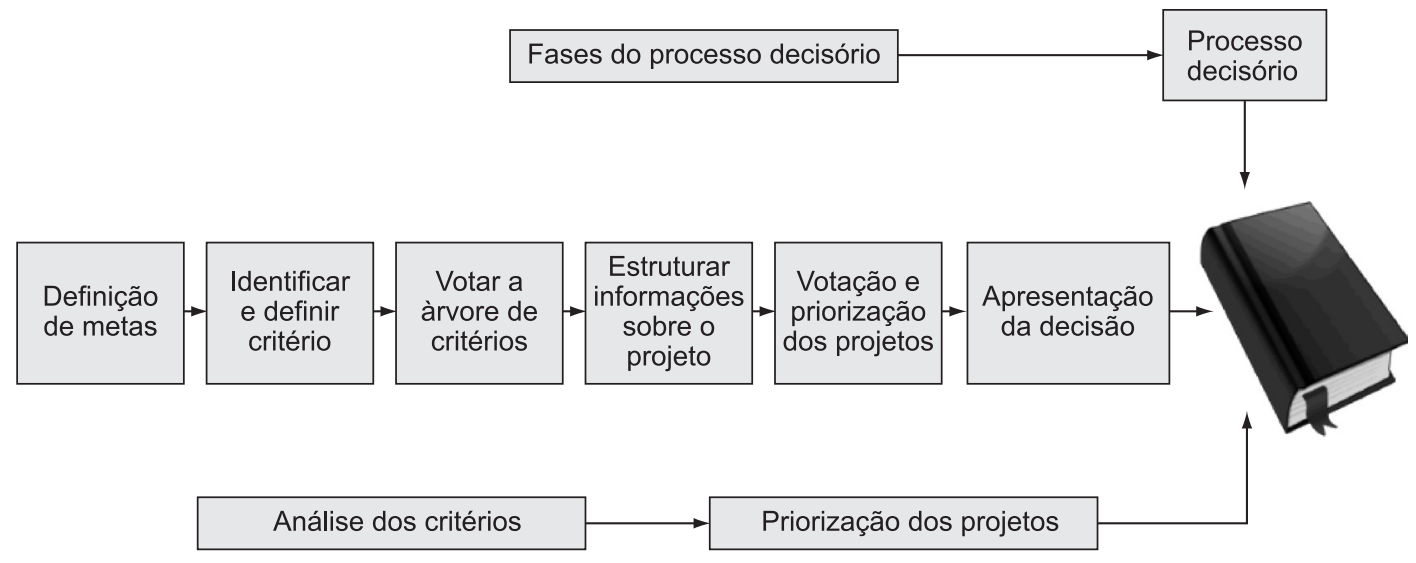

Figura 3. Fases do modelo de decisão - parametrização do Software (Fonte: figura do autor).

Tabela 1. Perfil dos Participantes das Reuniões de Concepção e Validação para cada classe de projeto.

\begin{tabular}{|c|c|c|c|c|c|c|}
\hline Grupo & Participantes & $\begin{array}{l}\text { Formação } \\
\text { básica }\end{array}$ & Especialização & $\begin{array}{c}\text { Tempo } \\
\text { formado } \\
\text { (anos) }\end{array}$ & $\begin{array}{c}\text { Tempo de } \\
\text { empresa } \\
\text { (anos) }\end{array}$ & $\begin{array}{c}\text { Tempo } \\
\text { no cargo } \\
\text { (anos) }\end{array}$ \\
\hline \multirow[t]{2}{*}{ P\&D } & $\begin{array}{l}\text { Gerente de desenvolvimento } \\
\text { de produtos }\end{array}$ & Eng. Química & Mestrado & 30 & 15 & 2 \\
\hline & $\begin{array}{l}\text { Gerente de aplicações de } \\
\text { produtos I }\end{array}$ & Química & Mestrado & 15 & 13 & 2 \\
\hline \multirow[t]{4}{*}{ Manutenção } & Chefe de manutenção fábrica 1 & Eng. Mecânica & $\begin{array}{c}\text { Especialista } \\
\text { Projetos (PMI) }\end{array}$ & 20 & 18 & 10 \\
\hline & Chefe de manutenção fábrica 2 & Eng. Química & MBA & 10 & 10 & 2 \\
\hline & Chefe de manutenção fábrica 3 & Eng. Mecânica & MBA & 10 & 10 & 5 \\
\hline & Chefe de manutenção fábrica 4 & Eng. Mecânica & Mestrado & 30 & 30 & 15 \\
\hline \multirow[t]{4}{*}{ Engenharia } & $\begin{array}{l}\text { Gerente de processos e } \\
\text { tecnologia }\end{array}$ & Eng. Química & Mestrado & 30 & 30 & 5 \\
\hline & Gerente de processos & Eng. Química & MBA & 25 & 25 & 5 \\
\hline & $\begin{array}{l}\text { Gerente de implantação } \\
\text { de projetos }\end{array}$ & Eng. Mecânica & MBA & 25 & 15 & 5 \\
\hline & Assessor de tecnologia & Eng. Química & MBA & 35 & 35 & 5 \\
\hline Informática & Gerente de TI & Informática & & 20 & 20 & 15 \\
\hline \multirow[t]{2}{*}{ Diretoria } & Assessor de diretoria & Eng. Química & MBA & 36 & 36 & 2 \\
\hline & Diretor industrial & Eng. Química & MBA & 25 & 20 & 8 \\
\hline
\end{tabular}




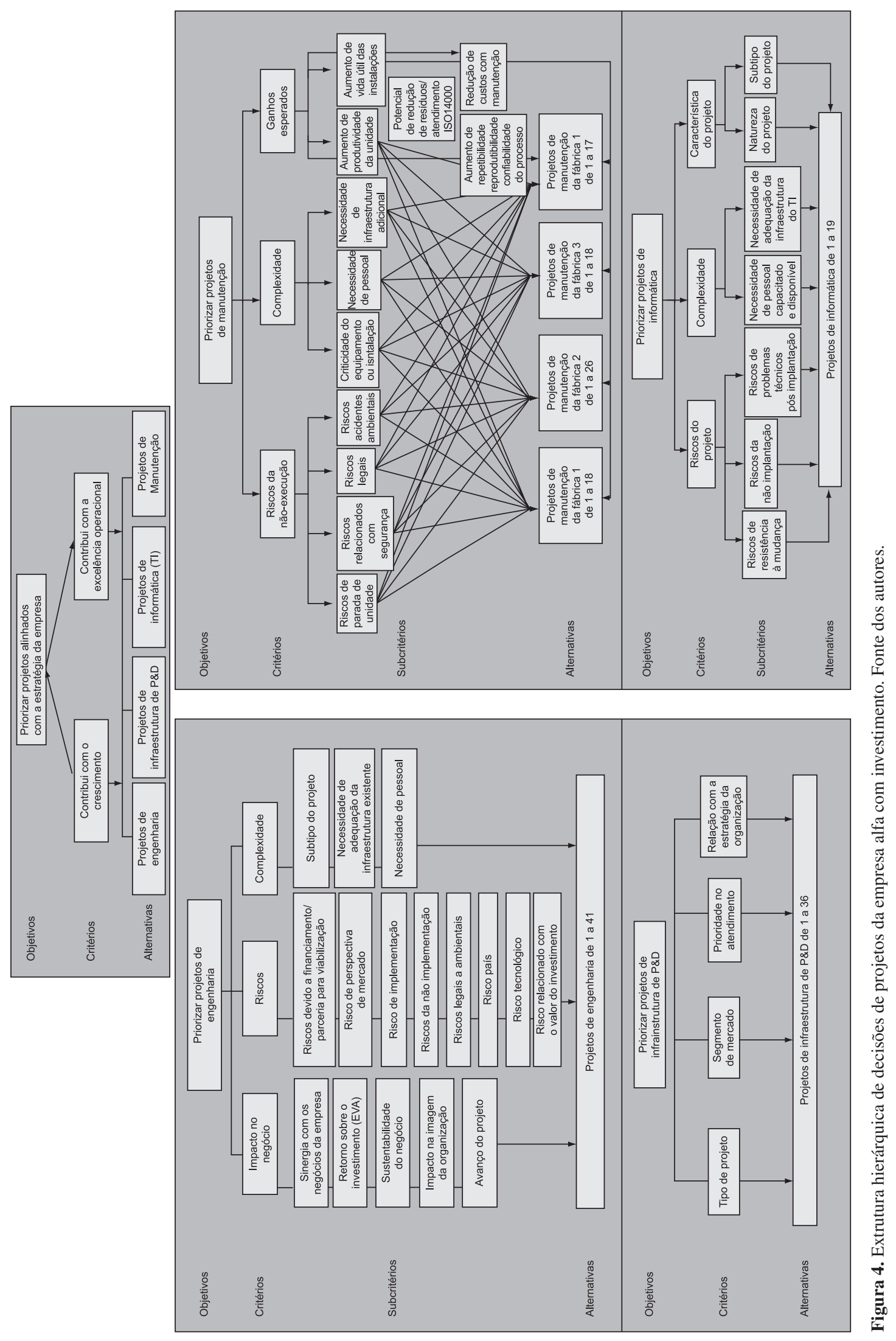




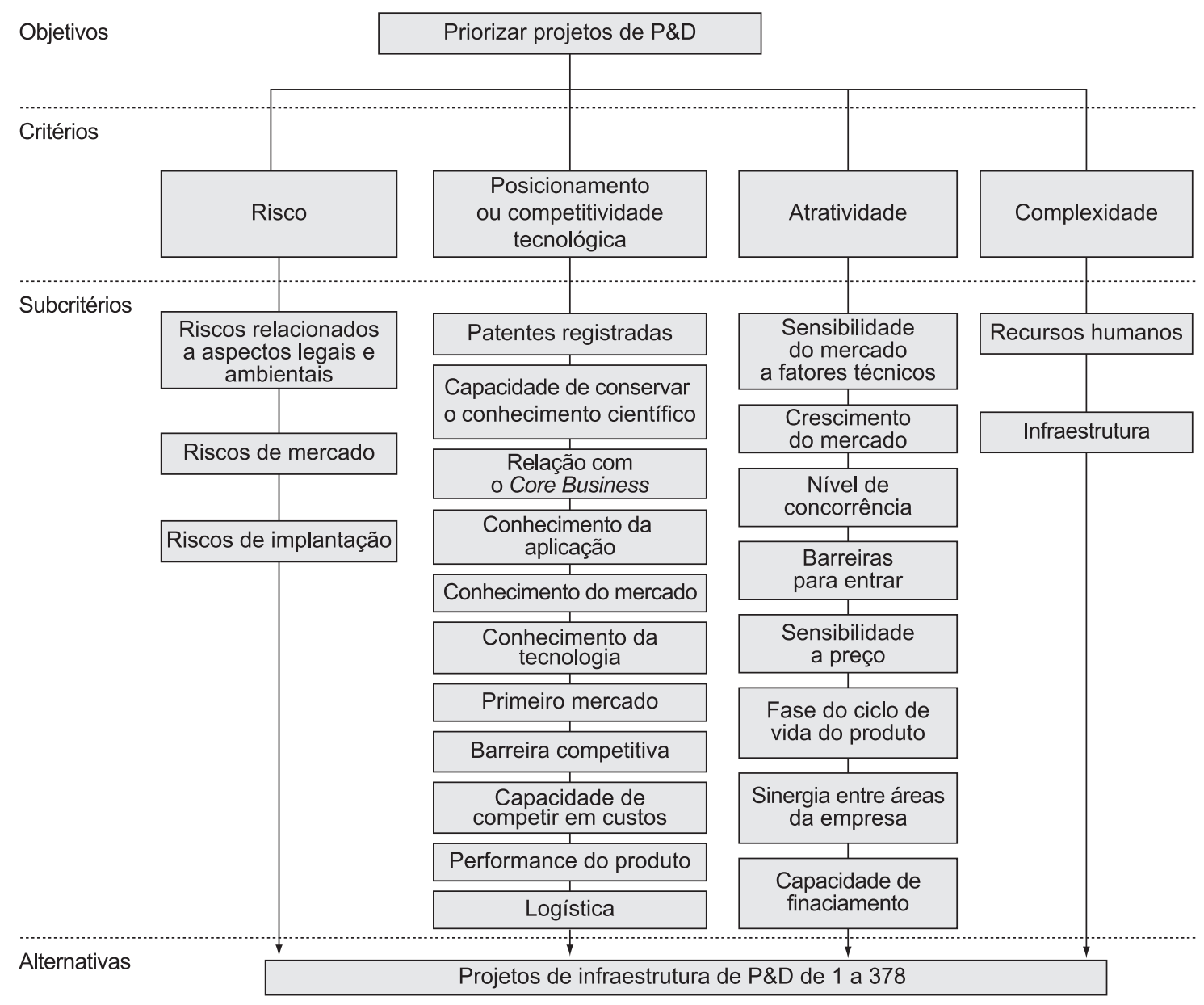

Figura 5. Estrutura hierárquica de decisões para projetos de P\&D da empresa - projetos sem investimento. Fonte: Autores.

validação com os membros do comitê definidos para os diferentes processos decisórios. Essa estratégia teve o objetivo de minimizar o número de reuniões com os funcionários da empresa, selecionados para atuarem como participantes na construção das diferentes estruturas de decisão, dado que havia grande dificuldade na conciliação de datas em que todos pudessem estar presentes.

Para a definição dos funcionários da empresa que participariam da concepção e validação da estrutura hierárquica de decisão de cada tipo de projeto, levaram-se em consideração os critérios de conhecimento que tinham sobre o assunto analisado, experiência, tempo de empresa, função que ocupavam na organização e disponibilidade. O perfil desses funcionários é apresentado na Tabela 1.

Cada funcionário que participou desta etapa era representante de um grupo de stakeholders primários da organização, sendo que sua decisão poderia interferir diretamente no resultado do trabalho.
Para avaliação do modelo foram utilizados os projetos relativos ao exercício de 2005, por estarem mais presentes na memória dos gestores, tornando mais fácil as discussões de priorização dos projetos. Para esses projetos, são dados conhecidos: o número de projetos, tipo, duração, escopo, os valores de orçamentos e valores reais desembolsados, EVA (Economic Value Added) e margem.

No total foram realizadas 8 reuniões com os diferentes participantes para a etapa de validação dos critérios de decisão, para cada estrutura de decisões, votação dos critérios e definição dos ratings e seus valores. Dessas reuniões, 3 foram com a equipe de manutenção, 2 com a equipe de $P \& D, 1$ com a equipe de Engenharia, 1 com o analista de negócio de TI e $1 \mathrm{com}$ a equipe da Diretoria.

A construção da estrutura de decisões de desenvolvimento de produtos de $\mathrm{P} \& \mathrm{D}$, projetos sem investimento, apresentada na Figura 5, foi baseada no modelo de seleção proposto por Lager (2002) e 
nos 32 critérios de atratividade e competitividade propostos por Jolly (2003). O critério de complexidade foi utilizado com o objetivo de incorporar no modelo as 3 dimensões de projetos propostas por McFarlan (1981), sendo elas: tamanho, experiência com tecnologia e estrutura do projeto. Também foram introduzidos na estrutura critérios já utilizados pela empresa e não identificados na literatura consultada. Como resultado da fase de votação dos pesos de cada critério e comparação dos critérios aos pares, obteve-se que o critério mais importante para seleção de projetos de P\&D é o posicionamento/ competitividade, seguido pelo critério de atratividade e em terceiro pela complexidade. Após a realização da análise de consistência da votação dos pesos dos critérios e criação da escala de valores de subcritérios, passou-se para a etapa de votação dos projetos. Como o número de projetos era grande, sendo 378 no total, verificou-se que o método AHP não era o mais indicado, pois havia muitas combinações para comparação por pares dos projetos para cada critério e subcritério. Por isso, foi sugerida a subdivisão dos projetos por área de negócio, sendo feitas votações para 5 diferentes áreas de negócios da empresa.

Para a estrutura da Figura 4, que articula a estrutura principal à estrutura das 4 categorias de projetos subordinadas, considerou-se a existência de um limite de investimentos a ser aprovado por ano, propôs-se aos participantes, durante a reunião de apresentação do modelo híbrido, que dessem pesos aos 2 objetivos estratégicos da organização, tendo como foco a priorização dos 4 tipos de projetos alinhados com a estratégia da empresa. Esses objetivos são denominados pela empresa de "crescimento", que está relacionado com ações para aumento de capacidade e "Excelência Operacional", que tem a ver com atividades de manutenção da infraestrutura instalada e melhorias. Na época em que o estudo foi feito, o objetivo de "Crescimento" era mais prioritário que "Excelência Operacional". Como resultado da priorização dos 4 grupos de projetos, os de engenharia eram os de maior peso, seguidos pelos de manutenção, ficando em terceiro os projetos de Infraestrutura de $\mathrm{P} \& \mathrm{D}$ e por último os de TI, conforme se pode verificar na Tabela 2. Os resultados obtidos se aproximaram das prioridades reais definidas pela empresa.
Para a construção da estrutura de decisões para os projetos de engenharia, foram selecionados 41 projetos. O esboço da estrutura foi baseado nos trabalhos de Roberts e Berry (1985) e Garcez (2005) sobre estratégias de crescimento; de McFarlan (1981) sobre riscos e classificação de projetos; além dos trabalhos de Archer e Ghasemzadeh (1999) sobre seleção de projetos; e de Cooper, Edgett, Kleinschmidt (1999) sobre métodos de gestão de portfólio. Durante a reunião para a validação da estrutura de engenharia, os participantes eliminaram a duração e a natureza do projeto da lista de subcritérios relacionados ao critério complexidade, existentes no esboço proposto. Eles não julgaram "duração" como sendo um critério de priorização válido para os projetos da empresa. Na literatura a duração também não foi identificada como critério de decisão. No caso da natureza dos projetos, apesar de ser um critério utilizado na priorização dos projetos pela organização, os participantes optaram por excluí-lo. Essa decisão dos participantes diverge da teoria, em que a natureza dos projetos, embora com outra denominação, está relacionada com o alinhamento estratégico do projeto, sendo este um critério citado por diversos autores (CARVALHO; LAURINDO, 2003; ROUSSEL et al., 1991; COOPER; EDGETT; KLEINSCHMIDT, 1999, 2001). Ao observar a estrutura de projetos de engenharia obtida, um dos autores que conduziu a reunião argumentou que o subcritério "Avanço do Projeto" não era recomendado pela literatura por induzir os participantes a cair nas armadilhas de decisão relatadas por Hammond et al. (1998). A introdução de uma restrição, em que projetos já iniciados têm peso maior que os projetos novos, poderia levar a empresa a continuar investindo em projetos que não valessem a pena, caindo na armadilha do custo afundado (sunk-cost). Mesmo após essa argumentação, os participantes optaram por manter o subcritério "Avanço do Projeto" na estrutura de decisões. Essa decisão nos leva a supor que os participantes tenham caído na armadilha da âncora, pois, ao final das votações, este subcritério foi o de maior peso dentro do critério "Impacto no Negócio".

No caso dos projetos de manutenção, na etapa de análise do coeficiente de inconsistência na votação dos critérios, "Riscos da Não Execução"

Tabela 2. Pesos dos projetos da estrutura principal.

\begin{tabular}{llccc}
\hline Ordem & \multicolumn{1}{c}{ Alternativas } & Score & Crescimento 0,71 & Excelência operacional 0,21 \\
\hline 1 & Projetos de Engenharia & 0,51 & 0,70 & 0,05 \\
2 & Projetos de Manutenção & 0,22 & 0,05 & 0,64 \\
3 & Projetos de Infraestrutura de P\&D & 0,18 & 0,18 & 0,20 \\
4 & Projetos de TI & 0,09 & 0,08 & 0,11 \\
\hline
\end{tabular}


versus "Ganhos Esperados" concluiu-se que foi dado um peso excessivo para os Riscos da Não Execução. Retornando-se à comparação por pares na votação destes subcritérios, foi possível verificar que os participantes das fábricas 2 e 3 deram os maiores pesos para os Riscos da Não Execução, puxando a média para um valor mais alto. Esses dois participantes, sendo os menos experientes na função de chefia da manutenção podem ter originado essa tendência. Uma observação dos próprios participantes durante a discussão do motivo do peso elevado atribuído ao critério "Riscos da Não Execução" foi que as notas dadas não representavam a estratégia da empresa e sim o que os participantes acreditavam ser eticamente correto, por isso, ao final da discussão, as notas acabaram sendo alteradas, resultando num peso pouco menor para o subcritério "Riscos da Não Execução" quando comparado com os "Ganhos Esperados". No caso dos projetos de manutenção, o representante de cada unidade fabril votou apenas os projetos de sua unidade. Eles afirmaram não ter condições de julgar a relevância de um projeto de outra fábrica. Por isso, foi estabelecido um critério de rateio do montante de investimento por site, proporcional ao valor se seus ativos. Este critério de rateio foi acordado entre os participantes da reunião e é um fator de distorção nos resultados finais dos projetos de manutenção selecionados. Entretanto esta foi a forma encontrada pelos autores para eliminarem a restrição para a continuidade dos trabalhos.

No caso da validação da estrutura de projetos de TI, os mesmos passos já apresentados foram seguidos, tendo-se observado que a definição do escopo de alguns projetos não era precisa, por isso, o decisor não conseguia votar o projeto. Assim, como fruto deste trabalho, foi realizada uma revisão da forma de apresentação dos projetos de TI para aprovação.

Após a construção e validação das estruturas de decisão por tipo de projeto, foi introduzida a restrição de orçamento e que foi simulada para diferentes cenários com o uso da Programação Inteira e comparada com o cenário real, utilizando o valor do investimento aprovado para o ano de 2005. Tais cenários de simulação utilizaram Programação Inteira e binária do tipo 0 ou 1 . Em alguns dos cenários simulados para os projetos de engenharia, foram estabelecidas relações de dependência entre os projetos de tal forma que projetos que requeriam a execução de outros projetos ou que precisassem ser realizados juntos ou numa dada relação de precedência fossem assim priorizados. Também foram simulados cenários utilizando-se de rateios dos valores dos investimentos por subtipo de projeto para os projetos de engenharia e manutenção.
Após a aplicação da Programação Inteira e das restrições, foram obtidos os resultados de quais projetos teriam sido selecionados em cada cenário, com o uso do AHP e com o modelo híbrido. Tais resultados foram comparados com os resultados que ocorreram na prática, considerando-se que os dados utilizados são de eventos passados. Os resultados obtidos foram apresentados aos gestores que participaram das etapas de elaboração das estruturas e validação modelo. Tais resultados estão no anexo deste artigo e apresentam respectivamente as seguintes simulações: projetos de infraestrutura de P\&D (Quadro 2), projetos de TI (Quadro 3), projetos de engenharia (Quadro 4), projetos de manutenção - fábrica 1 (Quadro 5), projetos de manutenção - fábrica 2 (Quadro 6), projetos de manutenção - fábrica 3 (Quadro 7), projetos de manutenção - fábrica 4 (Quadro 8).

A simulação dos projetos de infraestrutura de P\&D (Quadro 2) mostra os casos em que 50\% do orçamento é dado como teto e do cenário real. Pelo que se pode constatar, o uso do método AHP integrado à programação inteira permite uma melhor alocação dos recursos disponíveis, conforme observado por Greiner e Fowler (2003). O caso real mostra que $32,84 \%$ dos recursos solicitados foram utilizados, fato que indica uma baixa capacidade de execução da área de P\&D. Verifica-se, também, que os valores gastos são muito diferentes dos solicitados, podendo existir ou uma baixa qualidade na elaboração das estimativas dos investimentos ou gastos dos valores concedidos em contas diferentes das propostas. Archer e Ghasemzadeh (1999) propõem que uma das causas desses problemas seja a utilização de modelos de gestão que não contemplam a reavaliação periódica dos projetos. Outra possível causa dos grandes desvios entre os valores reais gastos por projeto é que o gestor responsável por eles tenha caído na armadilha do custo afundado relatada por HAMMOND; KEENEY; RAIFFA (1998). Os resultados encontrados estão de acordo com Saaty (1991) que afirma que o uso do método AHP permite ao decisor entender melhor a complexidade do processo de decisão, tendo o potencial de melhorar a qualidade da decisão.

Para os projetos de ti (Quadro 3), em que somente a alocação integral dos valores propostos é aceita, não foram alocados valores para os projetos 2303 e 2331. Quando é permitida a alocação parcial de recursos, o projeto 2151 , com a maior prioridade passou a ter alocação parcial, com $85,9 \%$ do valor total orçado e o projeto 2303 , que no cenário (1) não tinha sido contemplado, passou a ter alocação integral dos recursos solicitados. O projeto 2331 não teve recursos alocados em nenhum dos dois cenários de simulação, porém, no cenário real, 
Quadro 2. Resultado das simulações dos cenários de Projetos de Infraestrutura de P\&D.

\begin{tabular}{|c|c|c|c|c|c|c|c|}
\hline \multicolumn{4}{|c|}{ Projetos de Infraestrutura de P\&D } & \multicolumn{2}{|c|}{ Cenário (1) } & \multicolumn{2}{|c|}{ Cenário Real } \\
\hline Seq. & Projeto & Prioridade & $\begin{array}{l}\text { Valor solicitado } \\
\text { (US\$) }\end{array}$ & $\begin{array}{c}\text { Valor atribuído } \\
\text { (US\$) }\end{array}$ & $\begin{array}{c}\% \\
\text { atribuído }\end{array}$ & $\begin{array}{l}\text { Valor atribuído } \\
\text { (US\$) }\end{array}$ & $\begin{array}{c}\% \\
\text { atribuído }\end{array}$ \\
\hline 1 & 2204 & 0,741 & 186.100 & 186.100 & 100 & 98.210 & 52,77 \\
\hline 2 & 2223 & 0,741 & 500 & 500 & 100 & 13.661 & 2732,14 \\
\hline 3 & 2224 & 0,34 & 1.000 & 999 & 100 & 31.338 & 3133,84 \\
\hline 4 & 2228 & 0,22 & 400 & 399 & 100 & 2.833 & 708,32 \\
\hline 5 & 2229 & 0,263 & 5.000 & 5.000 & 100 & 21.216 & 424,32 \\
\hline 6 & 2230 & 0,263 & 5.000 & 5.000 & 100 & 43.090 & 861,80 \\
\hline 7 & 2231 & 0,317 & 100 & 100 & 100 & 360 & 360,48 \\
\hline 8 & 2233 & 0,925 & 3.300 & 3.300 & 100 & 7.764 & 235,28 \\
\hline 9 & 2237 & 0,239 & 44.000 & 44.000 & 100 & 23.469 & 53,34 \\
\hline 10 & 2319 & 0,34 & 5.000 & 5.000 & 100 & 3.500 & 70,00 \\
\hline 11 & 2325 & 0,239 & 4.500 & 4.500 & 100 & 3.400 & 75,56 \\
\hline 12 & 2344 & 0,239 & 139.300 & 139.300 & 100 & 29.110 & 20,90 \\
\hline 13 & 2353 & 0,165 & 75.000 & 75.000 & 100 & 0 & 0,00 \\
\hline 14 & 2365 & 1 & 84.500 & 84.500 & 100 & 16.090 & 19,04 \\
\hline 15 & 2369 & 0,321 & 25.000 & 25.000 & 100 & 0 & 0,00 \\
\hline 16 & 2381 & 0,298 & 169.000 & 168.999 & 100 & 168.780 & 99,87 \\
\hline 17 & 2398 & 0,528 & 2.227 .700 & 1.878 .853 & 84,3 & 273.220 & 12,26 \\
\hline 18 & 4604 & 0,505 & 34.000 & 34.000 & 100 & 76.285 & 224,37 \\
\hline 19 & 4706 & 0,977 & 82.700 & 82.700 & 100 & 33.000 & 39,90 \\
\hline 20 & 2306 & 0,329 & 40.900 & 40.900 & 100 & 26.870 & 65,70 \\
\hline 21 & 2308 & 0,505 & 18.100 & 18.100 & 100 & 0 & 0,00 \\
\hline 22 & 2312 & 0,793 & 12.500 & 12.500 & 100 & 10.900 & 87,20 \\
\hline 23 & 2333 & 0,22 & 47.100 & 47.100 & 100 & 0 & 0,00 \\
\hline 24 & 2338 & 0,317 & 500 & 500 & 100 & 580 & 116,00 \\
\hline 25 & 2342 & 0,317 & 13.700 & 13.700 & 100 & 9.570 & 69,85 \\
\hline 26 & 2347 & 0,317 & 180.000 & 179.999 & 100 & 0 & 0,00 \\
\hline 27 & 2359 & 0,317 & 11.500 & 11.500 & 100 & 9.260 & 80,52 \\
\hline 28 & 2360 & 0,24 & 40.200 & 40.200 & 100 & 45.820 & 113,98 \\
\hline 29 & 2364 & 0,524 & 30.000 & 30.000 & 100 & 0 & 0,00 \\
\hline 30 & 2375 & 0,317 & 45.000 & 44.999 & 100 & 19.950 & 44,33 \\
\hline 31 & 2376 & 0,718 & 121.500 & 121.500 & 100 & 136.000 & 111,93 \\
\hline 32 & 2380 & 0,77 & 17.200 & 17.200 & 100 & 2.890 & 16,80 \\
\hline 33 & 2388 & 0,524 & 18.400 & 18.400 & 100 & 5.390 & 29,29 \\
\hline 34 & 2234 & 0,317 & 95.000 & 94.999 & 100 & 0 & 0,00 \\
\hline 35 & 4889 & 0,317 & 1.000 & 1.000 & 100 & 4.050 & 405,00 \\
\hline 36 & 4999 & 0,317 & 15.000 & 14.999 & 100 & 16.760 & 111,73 \\
\hline Totais & & & 3.799 .700 & 3.450 .846 & & 1.133 .367 & \\
\hline$\%$ Por & fólio & & 110,11 & 100,00 & & 32,84 & \\
\hline
\end{tabular}

recebeu $84,22 \%$ do valor solicitado. Verifica-se que o cenário (2) permite uma melhor utilização dos recursos disponíveis, tendo $100 \%$ dos projetos contemplados. Esse resultado foi o mesmo encontrado por Greiner e Fowler (2003). Ao analisar o cenário real, pôde-se observar que a utilização dos recursos teve desempenho pior que os cenários (1) e (2). Verificou-se também que os projetos 2216 e 2220 gastaram muito mais do que o valor aprovado. Esse "estouro" foi compensado pela opção de não se concluir os demais projetos, para garantir que o orçamento global da área de informática não fosse superior ao teto aprovado.

No caso dos projetos de engenharia (Quadro 4), foram simulados 5 cenários. O cenário (1) utilizou a programação inteira do tipo 0 ou 1 , também chamada 
Quadro 3. Resultado das simulações dos cenários de Projetos de TI.

\begin{tabular}{|c|c|c|c|c|c|c|c|c|c|}
\hline \multicolumn{4}{|c|}{ Projetos de Informática } & \multicolumn{2}{|c|}{ Cenário 1} & \multicolumn{2}{|c|}{ Cenário 2} & \multicolumn{2}{|c|}{ Cenário Real } \\
\hline Seq. & Projeto & Prioridade & $\begin{array}{c}\text { Valor } \\
\text { solicitado } \\
\text { (US\$) }\end{array}$ & $\begin{array}{c}\text { Valor } \\
\text { atribuído } \\
\text { (US\$) }\end{array}$ & $\begin{array}{c}\% \\
\text { atribuído }\end{array}$ & $\begin{array}{c}\text { Valor } \\
\text { atribuído } \\
\text { (US\$) }\end{array}$ & $\begin{array}{c}\% \\
\text { atribuído }\end{array}$ & $\begin{array}{c}\text { Valor } \\
\text { atribuído } \\
\text { (US\$) }\end{array}$ & $\begin{array}{c}\% \\
\text { atribuído }\end{array}$ \\
\hline 1 & 2151 & 0,689 & 1.133 .000 & 1.133 .000 & 100 & 973.720 & 85,9 & 1.005 .860 & 88,78 \\
\hline 2 & 2216 & 0,324 & 21.000 & 21.000 & 100 & 20.999 & 100 & 43.780 & 208,48 \\
\hline 3 & 2220 & 0,223 & 47.000 & 47.000 & 100 & 46.999 & 100 & 55.836 & 118,80 \\
\hline 4 & 2303 & 0,324 & 181.200 & 0 & 0 & 181.199 & 100 & 152.600 & 84,22 \\
\hline 5 & 2331 & 0,223 & 490.400 & 0 & 0 & 0 & 0 & 64.400 & 13,13 \\
\hline 6 & 2391 & 0,421 & 52.000 & 52.000 & 100 & 52.000 & 100 & 22.900 & 44,04 \\
\hline 7 & 4840 & 0,648 & 77.000 & 77.000 & 100 & 77.000 & 100 & 44.935 & 58,36 \\
\hline 8 & 2217 & 0,324 & 18.000 & 18.000 & 100 & 18.000 & 100 & 11.264 & 62,58 \\
\hline 9 & 2318 & 0,324 & 84.400 & 84.400 & 100 & 84.400 & 100 & 48.600 & 57,58 \\
\hline 10 & 2341 & 0,324 & 14.800 & 14.800 & 100 & 14.799 & 100 & 10.650 & 71,96 \\
\hline 11 & 2322 & 0,324 & 22.200 & 22.200 & 100 & 22.200 & 100 & 11.300 & 50,90 \\
\hline 12 & 2335 & 0,324 & 4.000 & 4.000 & 100 & 4.000 & 100 & 0 & 0,00 \\
\hline 13 & 2218 & 0,324 & 27.000 & 27.000 & 100 & 27.000 & 100 & 19.840 & 73,48 \\
\hline 14 & 2313 & 0,324 & 96.900 & 96.900 & 100 & 96.900 & 100 & 88.080 & 90,90 \\
\hline 15 & 4655 & 0,241 & 20.000 & 20.000 & 100 & 20.000 & 100 & 16.406 & 82,03 \\
\hline 16 & 4959 & 0,391 & 6.400 & 6.400 & 100 & 6.400 & 100 & 4.935 & 77,11 \\
\hline 17 & 2310 & 0,289 & 23.000 & 23.000 & 100 & 22.999 & 100 & 9.690 & 42,13 \\
\hline 18 & 2328 & 0,324 & 43.900 & 43.900 & 100 & 43.899 & 100 & 24.300 & 55,35 \\
\hline 19 & 2349 & 0,324 & 12.900 & 12.899 & 100 & 12.899 & 100 & 9.400 & 72,87 \\
\hline \multicolumn{2}{|c|}{ Totais } & & 2.375 .100 & 1.703 .499 & & 1.725 .413 & & 1.644 .775 & \\
\hline \multicolumn{2}{|c|}{ \% Portfólio } & & 137,65 & 98,73 & & 100,00 & & 95,33 & \\
\hline
\end{tabular}

de programação binária, para otimizar a utilização do uso do orçamento de investimentos destinado aos projetos de engenharia. Para este cenário, não foram consideradas as relações de dependência entre os projetos. No cenário (2), para o mesmo conjunto de projetos, foi utilizada a programação matemática permitindo alocação parcial de recursos sem considerar a existência de relações de dependências entre os projetos. O cenário (3) foi simulado com as mesmas condições do cenário (1), porém acrescentando-se as relações de dependência existentes entre os projetos. A simulação do cenário (4) é similar ao cenário (2), considerando-se as dependências entre os projetos. Por último, o cenário (5), além de utilizar a programação binária e a relação de dependências entre os projetos, também foi incluído um rateio do total orçado para projetos de engenharia no valor de US\$ 19.554 .833 por subtipo de projeto. Os resultados dos diferentes cenários são apresentados no Quadro 4. Pelo que se pode observar, dos 41 projetos propostos, 5 não teriam nenhum valor alocado no cenário (1). Este é o caso dos projetos 4900, 2401, 2400, 2368 e 4949. Verifica-se que no cenário (1) foram contemplados projetos com prioridades maiores e produto da prioridade pelo valor solicitado menor. Assim projetos com valores estimados muito elevados não foram alocados, mesmo quando sua prioridade era alta. Analisando-se o cenário (2), no qual valores parciais poderiam ser atribuídos aos projetos, verifica-se que o projeto 4949 passou a ser contemplado com valor de $81 \%$ do total solicitado. O cenário (2) permitiu que $100 \%$ do orçamento de investimento fosse alocado, ao passo que o cenário (1) sendo mais restritivo, permitiu que apenas $93,81 \%$ do orçamento fosse alocado. Esse resultado também foi encontrado por Greiner e Fowler (2003) e na simulação dos projetos de infraestrutura de $P \& D$ e informática, parecendo ser independente do tipo de projeto analisado. No cenário (3), observa-se que o fato de se acrescentarem relações de dependências entre os projetos no modelo não teve reflexo na seleção dos projetos, obtendo-se o mesmo resultado encontrado no cenário (1). Ao se analisar o cenário (4), novamente se observa que o acréscimo da relação de dependências entre os projetos não alterou a sua seleção, nem o montante alocado, quando comparado como cenário (2). Na literatura consultada, não foi encontrada nenhuma referência sobre a influência da relação de dependências entre projetos no resultado da otimização obtido com o AHP e a programação 


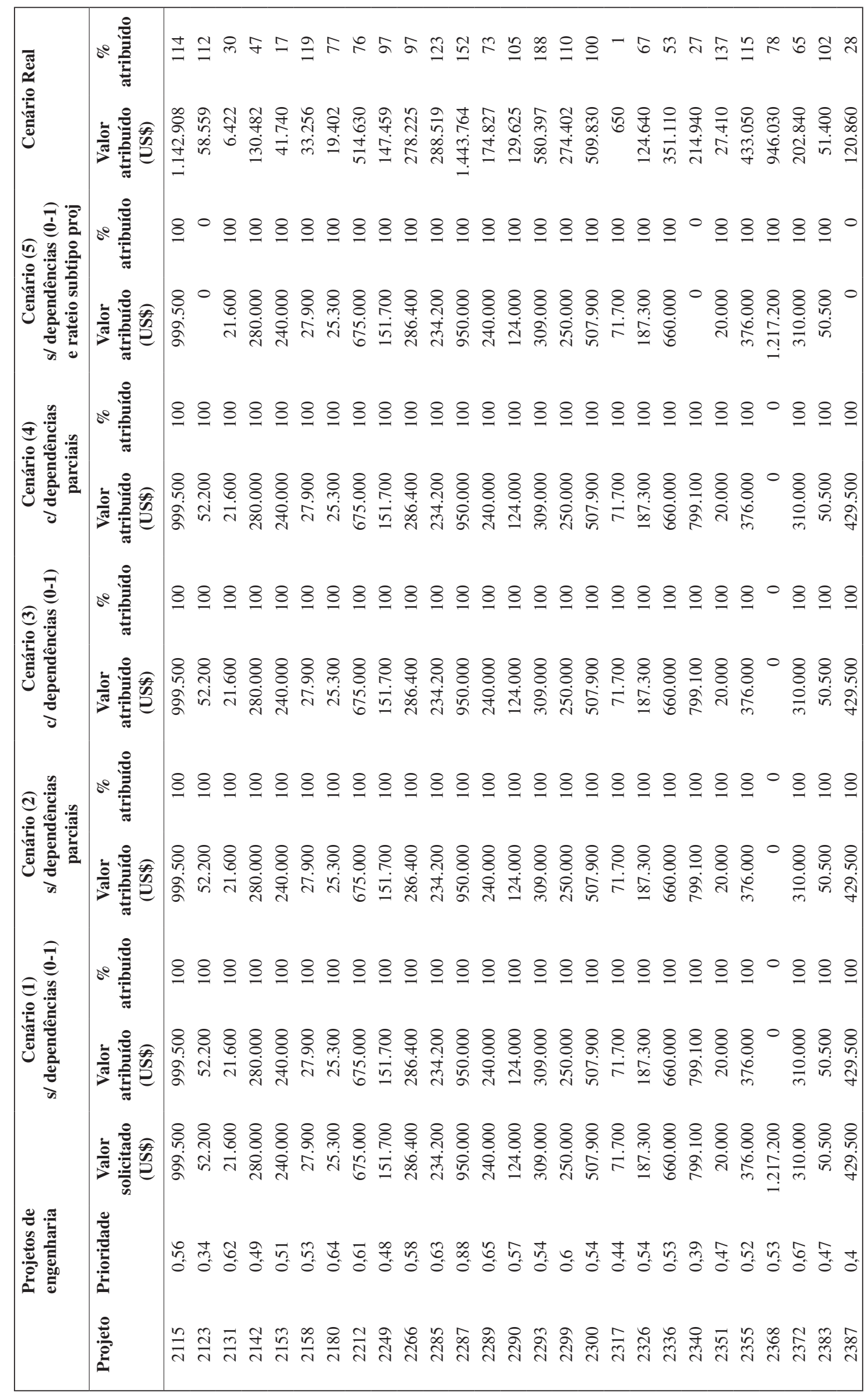




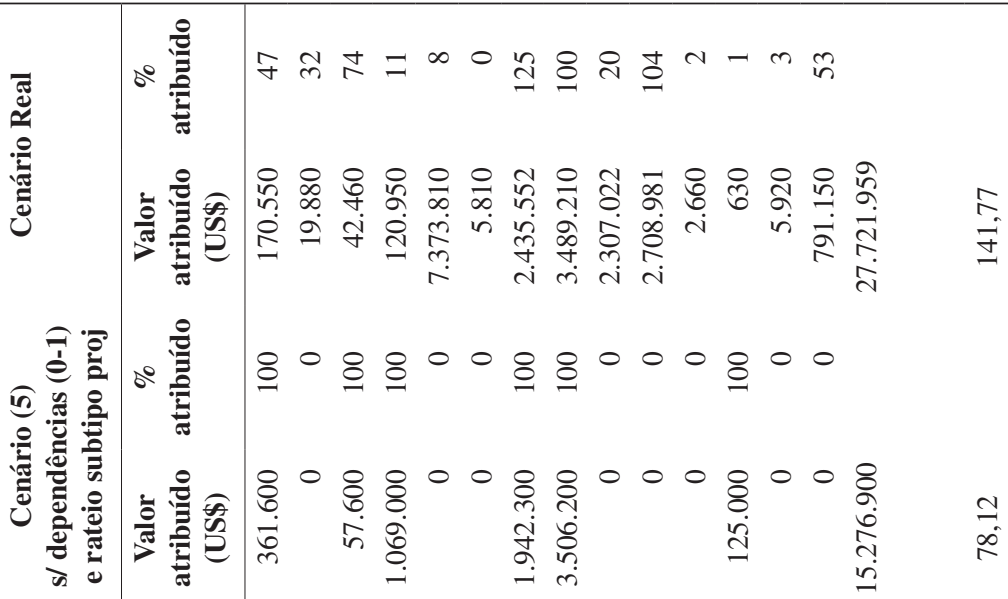

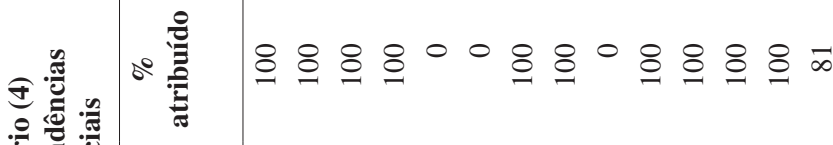

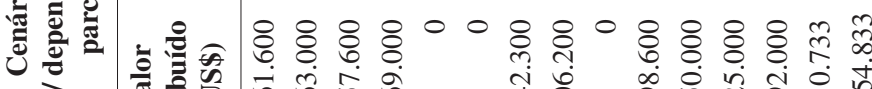

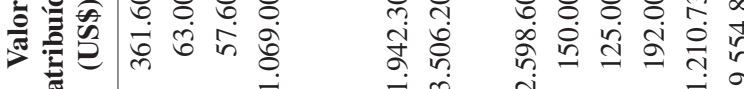

\&

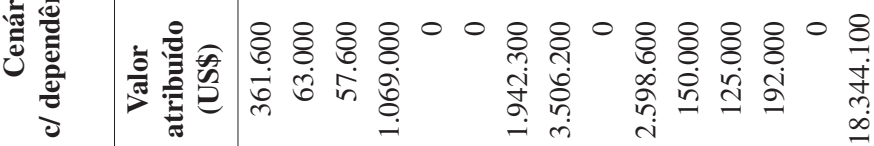

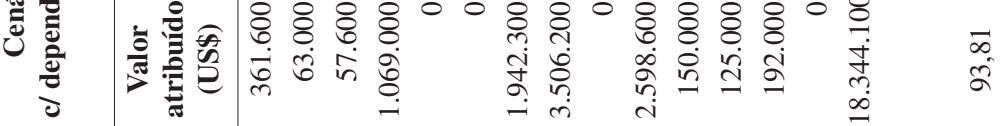

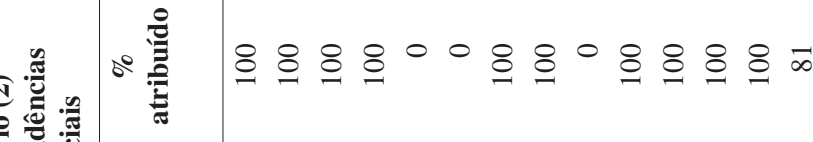

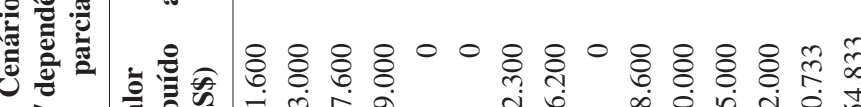

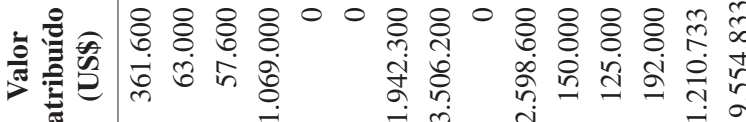

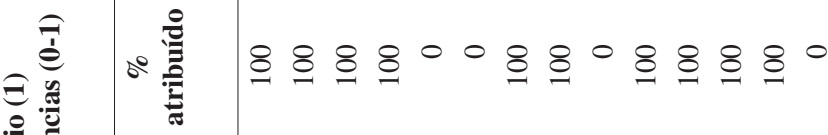

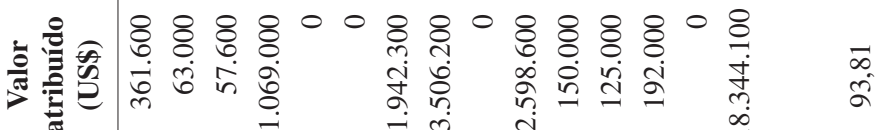

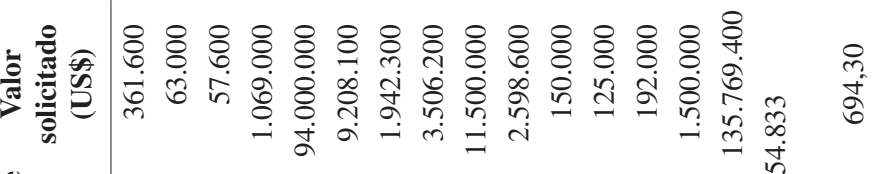

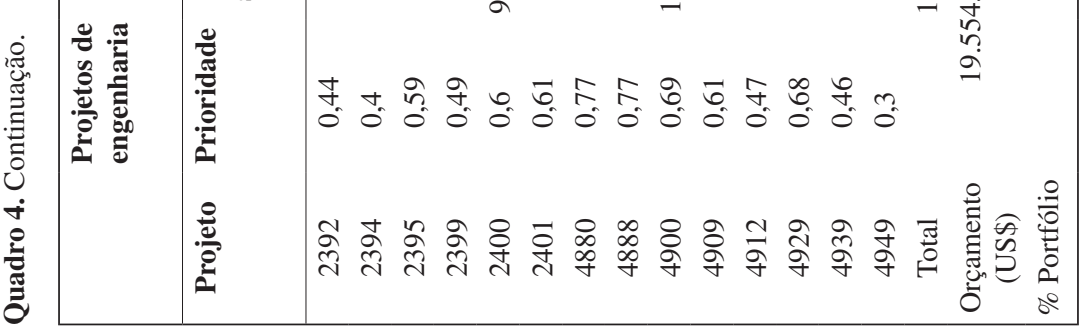


inteira integrados. Os projetos que não puderam ser alocados nos cenários de simulação são estratégicos para a empresa e, na prática, foram aprovados pela organização com recursos adicionais em período extraorçamentário. $\mathrm{O}$ fato dos projetos estratégicos não terem sido contemplados é devido à decisão de se excluir a natureza do projeto, se estratégico ou operacional, da estrutura de decisões de projetos de engenharia, problema já comentado anteriormente. Assim, para a estrutura de decisões de projetos de engenharia, os projetos só são priorizados pelo tipo e não pelo fato de contribuírem ou não com a estratégia da empresa. Verifica-se, por esse exemplo, que a definição dos critérios e dos subcritérios da estrutura de decisões impacta diretamente o resultado da seleção e priorização. Para a elaboração do cenário (5), foi estabelecido um critério de rateio do valor total disponível por subtipo de projeto. Este cenário teve como objetivo obter um portfólio balanceado em relação ao tipo de subprojeto, conforme recomendado na literatura sobre balanceamento de projetos. Os percentuais de cada subtipo de projeto utilizados são a média dos valores gastos com cada subtipo de projeto nos anos de 2001 a 2005. Com cenário o (5), chega-se a um resultado mais restritivo, no qual apenas $78,12 \%$ do orçamento foi alocado para o projetos. O Quadro 4 apresenta, ainda, o cenário real da empresa. Nele verifica-se que quase todos os projetos tiveram desembolsos, sendo que o valor total investido foi muito superior ao valor teto estabelecido na simulação de US\$19.554833, devido à alocação de todos os projetos que a empresa considera estratégicos. Observa-se também que parte dos projetos concluídos teve estouro nos valores estimados e a maior parte foi iniciada, porém não foi concluída. É possível concluir que com o uso do modelo proposto houve substancial melhoria no valor de portfólio, se considerados apenas os projetos operacionais. A inclusão dos projetos estratégicos na relação de projetos a serem priorizados pressupõe que todos os projetos fossem submetidos à nova priorização, passando novamente pelo filtro definido na Figura 3. O resultado encontrado foi diferente porque essa reavaliação dos projetos do portfólio não foi feita pela organização.

Os resultados das simulações dos cenários de investimentos em projetos de manutenção das 4 fábricas e os valores reais gastos com cada um dos projetos das 4 unidades industriais são apresentados nos Quadros 5 a 8. Para o portfólio de projetos de manutenção da fábrica 1 , os cenários que permitem a melhor alocação de recursos são os cenários (1) e (2), em que $100 \%$ dos projetos são contemplados. Esse resultado foi possível porque o valor total de investimentos disponível para essa unidade era maior do que o montante solicitado. Ainda analisando o
Quadro 5, podemos verificar que todos os cenários de simulação permitiram uma alocação de recursos melhor do que o cenário real, no qual apenas $40,42 \%$ dos recursos disponíveis foram utilizados. No cenário real a empresa iniciou todos os projetos, tendo concluído uma parte deles. Verifica-se que foram concluídos projetos de baixa prioridade, tal como o 2379 , ao passo que projetos de prioridade elevada foram iniciados, porém não foram concluídos, como ocorreu com os projetos 2126 e 2352. A fábrica 1 mostrou ter baixa capacidade de execução dos projetos, não conseguindo aproveitar os recursos disponibilizados (Quadro 5).

Para a fábrica 2 , que tem um valor máximo de investimento disponível menor que o solicitado, o cenário (2) foi o que permitiu a melhor alocação dos recursos disponíveis, permitindo a alocação parcial de recursos para projetos, sem que seja utilizado o rateio por subprojeto, pois esse rateio atua como uma restrição a mais. Ao fazermos a comparação dos resultados obtidos com o cenário real, observa-se que todos os projetos tiveram alocação, mesmo os 2251 e 2380, ambos com prioridade baixa. É possível verificar que muitos projetos tiveram gastos maiores que o previsto (\% atribuído maior que $100 \%$ ). A fábrica 2 demonstrou boa capacidade de execução dos projetos, pois investiu cerca de US\$ 2.500.000, excluindo-se o projeto 4600 , que é obrigatório por se tratar da construção de uma estação de tratamento de efluentes para adequação dos efluentes da unidade à legislação ambiental. Pode-se observar, ainda, que o projeto 4600 , sendo muito crítico, teve um tratamento diferenciado, tendo recebido uma parcela elevada do total solicitado em regime extraorçamentário. Neste caso, verifica-se que o uso do modelo para os 4 cenários auxilia na gestão dos projetos, pois estabelece metas de desembolso para cada projeto individualmente. $\mathrm{O}$ caso real, apesar de ter conseguido um bom desempenho em termos de alocação dos recursos financeiros, apresentou em muitos casos gastos superiores ao previstos, o que comprometeu a conclusão de outros projetos do portfólio (Quadro 6).

Para a fábrica 3, o cenário que permite o melhor uso dos recursos é o cenário (2), com alocação parcial dos recursos aos projetos, porém sem o uso de rateio por subprojeto, resultado também encontrado por Greiner e Fowler (2003). Nesse caso, o valor real gasto ficou muito próximo do resultado obtido com o cenário (2), sendo que 2 dos 3 projetos de maior prioridade foram concluídos. Os projetos $2373 \mathrm{e}$ 2301, que na simulação dos 4 cenários não foram contemplados, no cenário real obtiveram parte dos recursos solicitados. Esta unidade teve uma maior capacidade de execução de seus projetos, aproveitando bem os recursos concedidos (Quadro 6). 


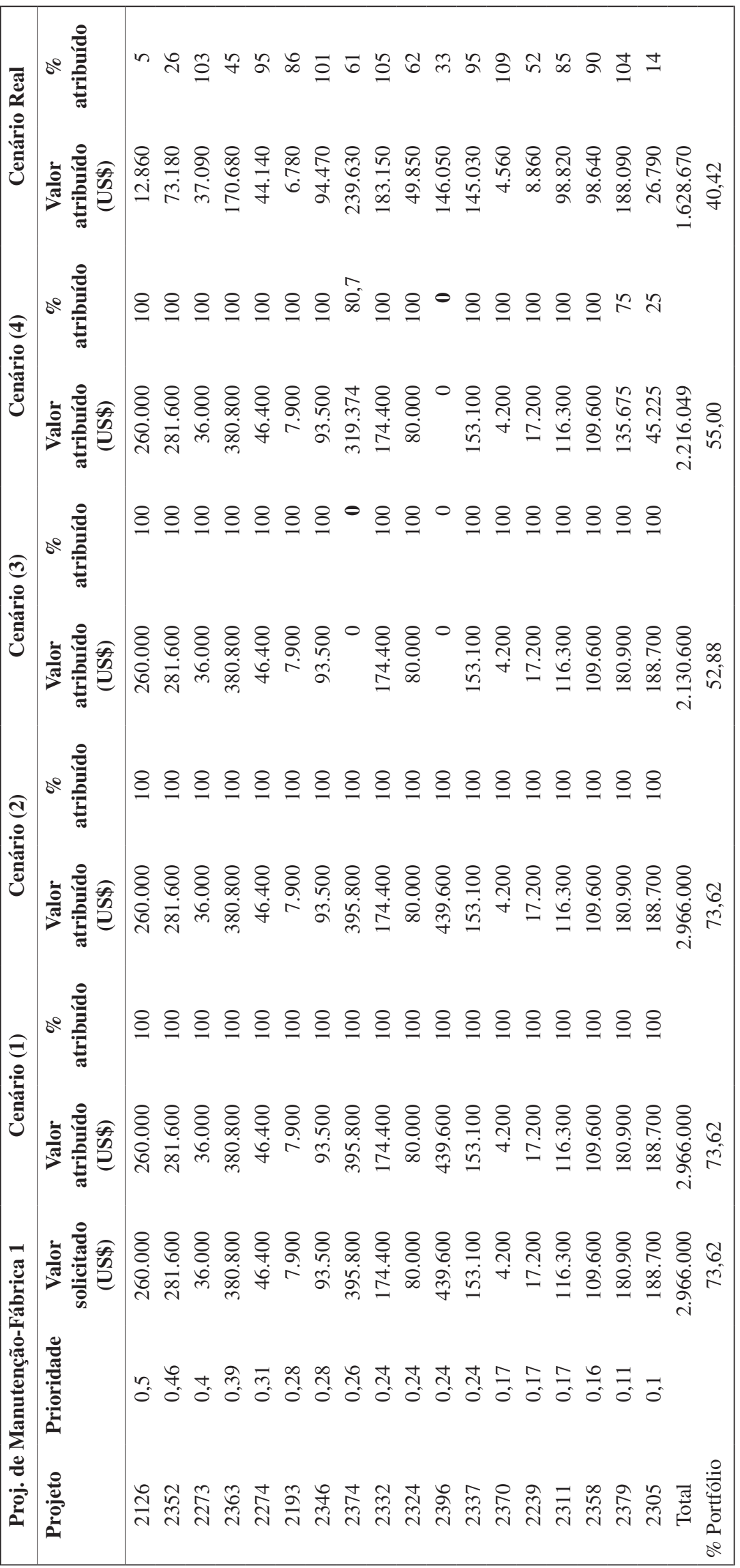




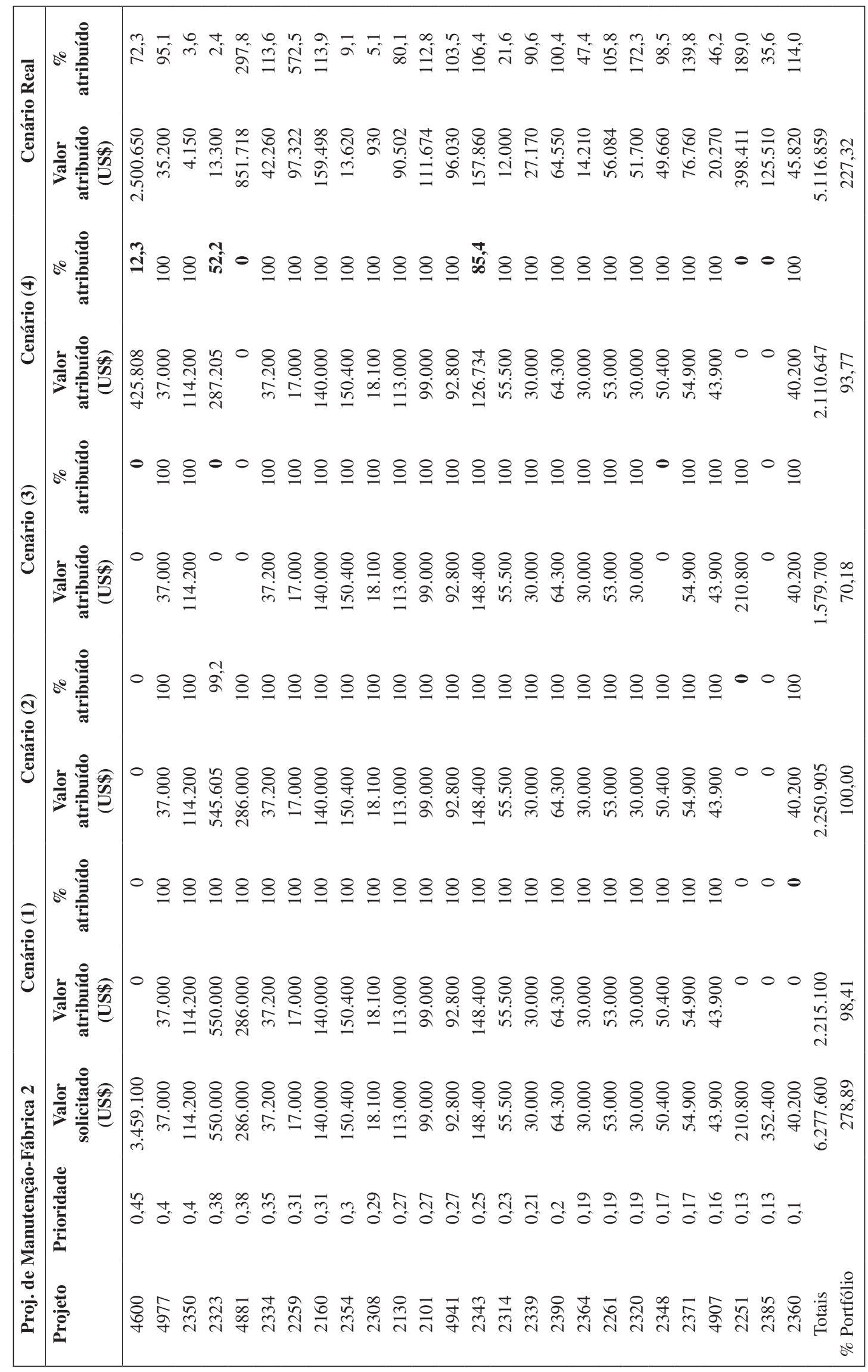




\begin{tabular}{|c|c|c|}
\hline נِ & 光总余 & 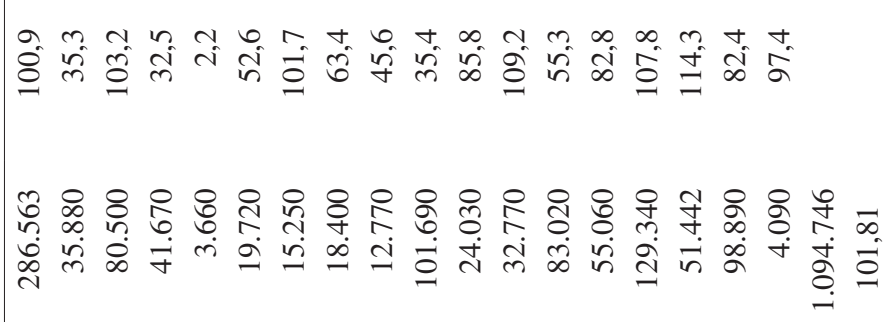 \\
\hline \pm & 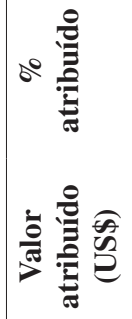 & 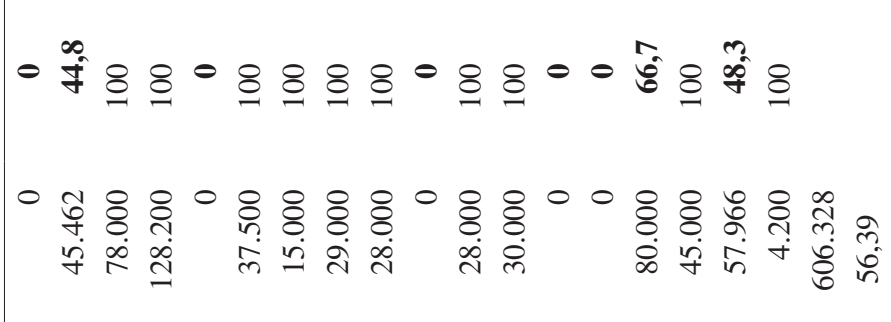 \\
\hline נֶ & 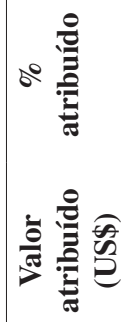 & 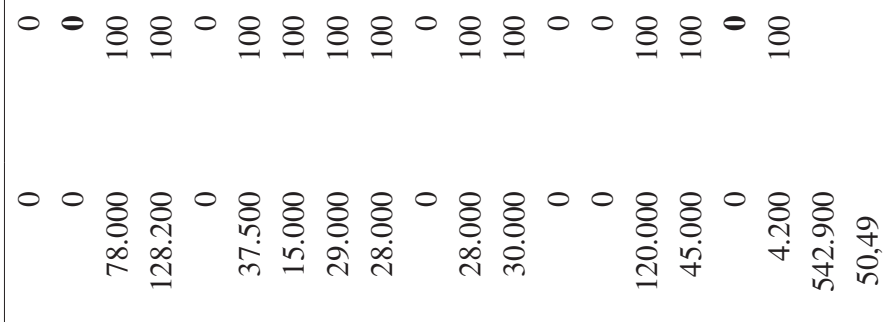 \\
\hline נִ & 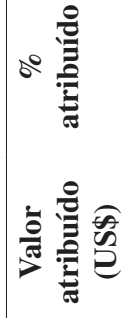 & 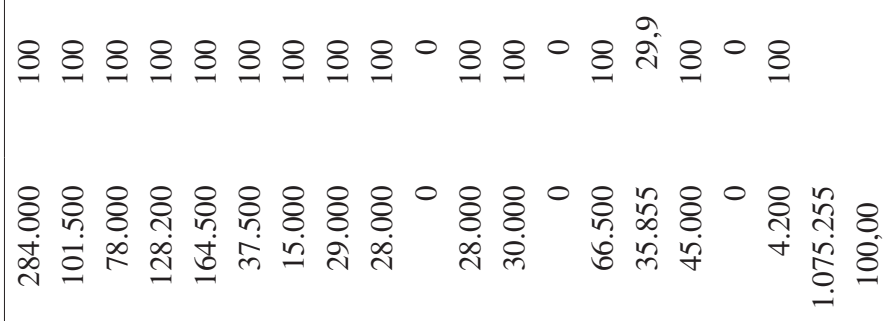 \\
\hline Uू: & 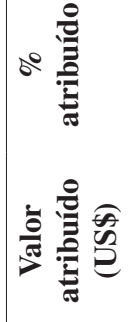 & 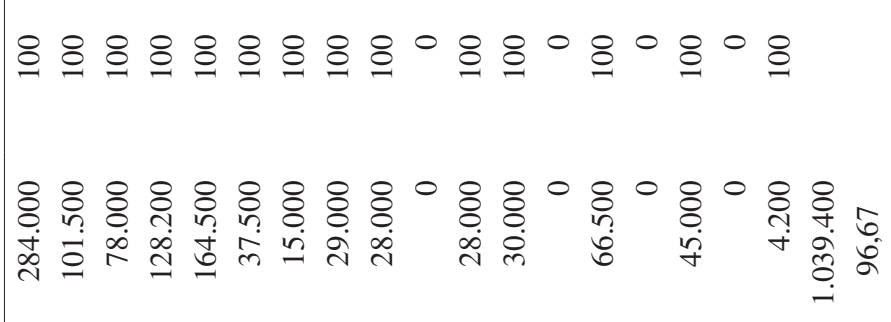 \\
\hline 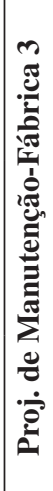 & 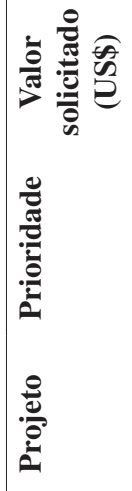 & 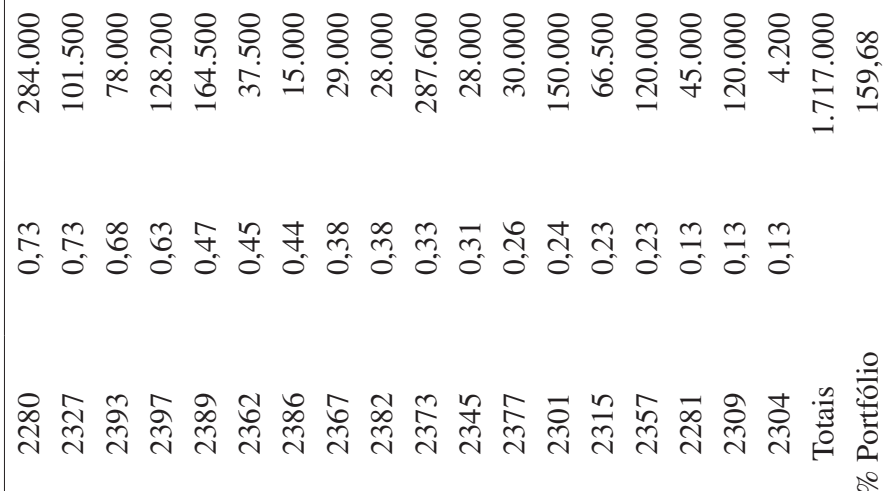 \\
\hline
\end{tabular}




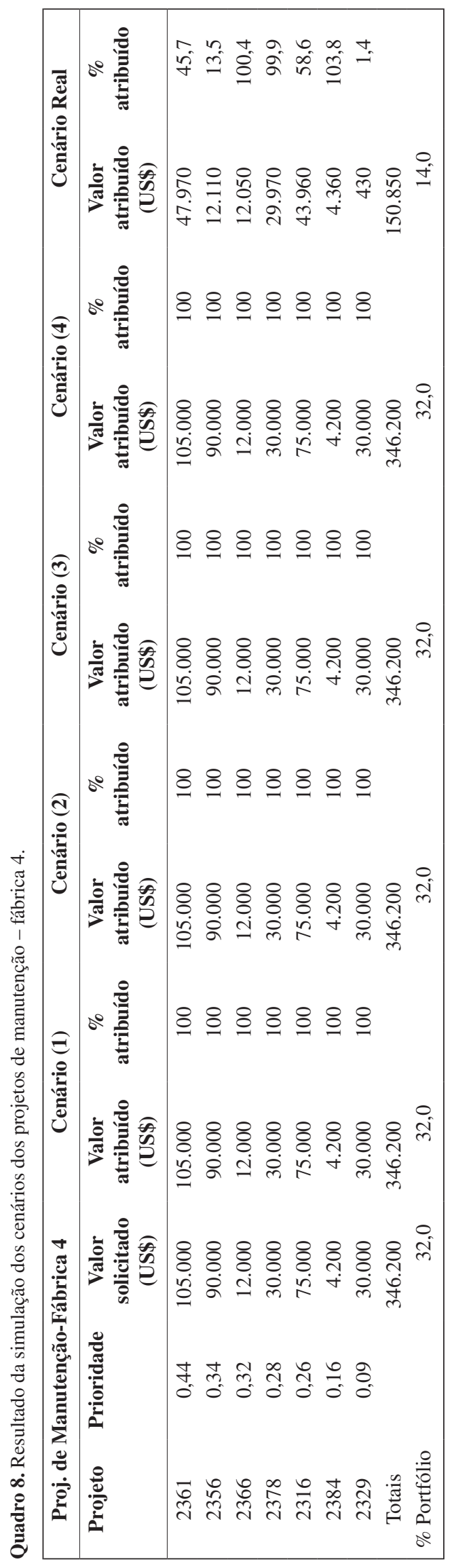


Por último, para a fábrica 4, em que o total de recursos disponível é maior que o solicitado, todos os cenários de simulação resultaram em alocação de $100 \%$ dos recursos. Apesar disso, o que foi solicitado, não foi realizado totalmente (Quadro 7).

\section{Conclusões}

Constatou-se por meio da simulação dos diferentes cenários com o caso real que a aplicação do modelo oferece aos gestores um processo de suporte à decisão eficiente para o tratamento de restrições, conforme descrito por Greiner e Fowler (2003), Archer e Ghasemzadeh (1999), Saaty (1991) e Forman e Selly (2001). O benefício do uso do AHP com um otimizador, observado nesta pesquisa, é a sua facilidade de estruturar o processo de tomada de decisão, pela elaboração de uma hierarquia de critérios de decisão durante reuniões de pequena duração com os decisores da organização estudada. Verificou-se também que o uso do modelo minimiza o risco do tomador de decisão cair nas armadilhas relatadas por Hammond; Keeney; Raiffa (1998) e observadas nas reuniões de concepção das estruturas de decisões, pois a discussão permite aprendizado aos participantes e a obtenção de consenso na definição de critérios e votação de prioridades. Pelo mesmo motivo, minimizam-se ou eliminam-se os problemas relatados por Nutt (2002), Garvin (2001) e Kaufmann (1975) no que tange aos jogos de poder. Devido às reuniões de brainstorming que fazem parte do método AHP, pôde-se comprovar que este método permite integração, compartilhamento de informações, comprometimento entre os decisores e aprendizado à equipe, conforme também observado por Greiner e Fowler (2003); Archer e Ghasemzadeh (1999); Saaty (1991); Forman e Selly (2001).

Observou-se que a eficácia do modelo depende do conhecimento dos participantes designados, pois devem ser stakeholders da organização. Conforme verificado durante a votação dos critérios de projetos de manutenção, a falta do conhecimento interferiu no resultado. A eficácia do modelo também depende da qualidade na definição de critérios, subcritérios, escala de valores e objetivos, conforme observado durante a votação dos projetos de TI.

O estudo mostrou que a viabilidade na aplicação do método AHP está relacionada com a existência na empresa de uma sistemática de classificação de projetos implantada, com dados confiáveis. O uso de diferentes metodologias de classificação de projetos, conforme proposto por Jolly (2003) e Archer e Ghasemzadeh (1999), possibilita que a análise do portfólio seja feita sob diferentes perspectivas e facilite a construção da estrutura de decisões do AHP. Por outro lado, observou-se que o método AHP não é o mais indicado para selecionar projetos quando o número de opções é superior a 100 projetos, pois as comparações aos pares levariam tempo muito grande, o que tornaria o processo pouco prático.

Foram limitações deste estudo: o uso de rateio de investimentos por planta no caso dos projetos de manutenção. Ao fazer o processo para os projetos de cada planta individualmente, provavelmente ocorreram distorções. O rateio de investimentos por planta é adotado pela empresa na prática.

Há indícios de que o modelo testado neste trabalho seja válido para qualquer tipo de portfólio de projetos, desde que os objetivos e critérios sejam revisados para cada caso. Entretanto, estudo com um maior número de empresas deve ser realizado para que esta suspeita seja comprovada.

Este trabalho nos deu a oportunidade de identificar a necessidade de estudos futuros com o objetivo de ampliar o conhecimento aqui abordado nos temas: 1) aplicação do modelo híbrido em ambiente com restrição de recursos humanos (HH por especialidade), dado que neste trabalho a restrição adotada foi de orçamento; 2) desenvolver um estudo sobre critérios de decisão e validade por tipo de organização e tipo de projetos, permitindo a criação de estrutura de decisões generalizadas por tipo de empresa, projeto ou negócio; 3) realizar estudo comparativo entre as diferentes metodologias de gestão de portfólio para se identificar quais as mais apropriadas e em quais condições.

\section{Referências}

ACKOFF, R. L. Planejamento empresarial. Rio de Janeiro: Livros Técnicos e Científicos, 1974.

ADNER, R.; LEVINTHAL, D. Demand heterogeneity and technology evolution: implications for product and process innovation. Management Science, v. 47, n. 5, p. 611-628, 2001.

ARCHER, N. P.; GHASEMZADEH, F. An integrated framework for project portfolio selection. International Journal of Project Management, v. 17, n. 4, p. 207-216, 1999.

BANERJEE, P. Resource dependence and core competence: insights from Indian Software Firms. Technovation, v. 23, n. 3, p. 251-263, 2003.

BROWN, S.; EISENHARDT, K. Competing on the edge: strategy as structured chaos. Boston: Harvard Business School Press, 1998.

BRYMAN, A. Research methods and organization studies. London: Unwin Hyman, 1989.

CARVALHO, M. M.; LAURINDO, F. J. B. Linking strategy with a network of performance indicators: a Brazilian Research Centre case study. International Journal of Business Performance Management, v. 5, n. 4, p. 285-301, 2003.

CARVALHO, M. M.; LAURINDO, F. J. B.; PESSOA, M. S. P. Information technology project management to achieve efficiency in Brazilian companies. In: KAMEL, S. (Org.). Managing Globally with Information Technology. Hershey: IGI Publishing, 2003. p. 260-271. 
CARVALHO, M. M.; LAURINDO, F. J. B. Estratégias para a competitividade. São Paulo: Futura, 2003.

CLEMEN, R. T. Making hard decisions. Duxbury: Press-Wadsworth, 1991.

COOPER, R.; EDGETT, S.; KLEINSCHMIDT, E. Portfolio management for new product development. R\&D Management, v. 31, n. 4, p. 361-380, 2001.

COOPER, R.; EDGETT, S.; KLEINSCHMIDT, E. New product management: practices and performance. Journal of Product Innovation Management, v. 16, n. 4, p. 333-351, 1999.

COOPER, R. G.; EDGETT, S. J.; KLEINSCHMIDT, E. J. Portfolio management in new product development. Research Technology Management, v. 40, n. 6, p. 16-28, 1997.

COOPER, R. G.; EDGETT, S. J.; KLEINSCHMIDT, E. J. Best practices for managing R\&D portfolios. Research Technology Management, v. 41, n. 4, p. 20-34, 1998.

COUGHLAN, P.; COGHLAN, D. Action research for operations management. International Journal of Operations \& Production Management, v. 22, n. 2, p. 230-240, 2002.

EISENHARDT, K. M.; BROWN, S. L. Patching restitching business portfolios in dynamic markets. Harvard Business Review, v. 77, n. 3, p. 72-82, 1999.

ELTON, J.; ROE, J. Bringing discipline to project management. Harvard Business Review, v. 76, n. 2, p. 153-157, 1998.

FORMAN, E.; SELLY, M. A. Decision by objectives: how to convince others that you are right. New Jersey: World Scientific, 2001.

GARBER, M. F. Estruturas flutuantes para a exploração de campos de petróleo no mar (FPSO): apoio à decisão na escolha do sistema. São Paulo, 2002. Dissertação (Mestrado) - Universidade de São Paulo - USP.

GARVIN, D. A.; ROBERTO, M. A. What you don't know about making decisions. Harvard Business Review, v. 79, n. 8, p. 108-116, 2001.

GOLDRATT, E. M. Corrente crítica. São Paulo: Livraria Nobel, 1998.

GREINER, M. A.; FOWLER, J. W. A hybrid approach using the analytic hierarchy process and integer programming to screen weapon systems projects. IEEE Transactions on Engineering management, v. 50, n. 2, p. 192-203, 2003.

HAMMOND, J. S.; KEENEY, R. L.; RAIFFA, H. The hidden traps in decision making. Harvard Business School, v. 76, n. 5, p. 47-58, 1998.

HSUAN, J.; HANSEN, P. K. Platform development: implications for portfolio management. Gestão e Produção, v. 14, n. 3, p. 453-461, 2007.

JOLLY, D. The issue of weightings in technology portfólio management. Technovation, v. 23, n. 5, p. 383-391, 2003.

KAUFMANN, A. A ciência da tomada de decisão. 2 ed. Rio de Janeiro: Zahar Editores, 1975.

LUEHRMAN, T. A. Strategy as a portfolio of real options. Harvard Business Review, v. 76, n. 5, p. 89-99, 1998.

MCFARLAN, F. W. Portfolio approach to information. Harvard Business Review, v. 59, n. 5, p. 142-150, 1981.
MIGUEL, P. A. C. Implementação da gestão de portfólio de novos produtos: um estudo de caso. Produção, v. 18, n. 2, p. 388-404, 2008.

MORAES, R. O.; LAURINDO, F. J. B. Um estudo de caso de gestão de portfólio de projetos de tecnologia da informação. Gestão e Produção, v. 10, n. 3, p. 311-328, 2003.

NUTT, P. C. Formulation tactics and the success of organizational decision making. Decision Sciences, v. 23, n. 3, p. 519-540, 1992.

PADOVANI, M.; CARVALHO, M. M.; MUSCAT, A. R. N. Portfolio management implementation in a chemistry Brazilian company. In: ANNUAL CONFERENCE OF THE PRODUCTION AND OPERATIONS MANAGEMENT, 2006, Boston. Proceedings... Boston: MAPOMS, 2006.

PADOVANI, M.; CARVALHO, M. M.; MUSCAT, A. R. N. Critical gaps in portfolio management implementation: a Brazilian case study. In: PORTLAND INTERNATIONAL CONFERENCE ON MANAGEMENT OF ENGINEERING AND TECNOLOGY, 2006, Istambul. Proceedings...

PRAHALAD, C. K.; HAMEL, G. The core competence of the corporation. Harvard Business Review, v. 68, n. 3, p. 79-91, 1990.

RABECHINI JÚNIOR, R.; MAXIMIANO, A. C. A.; MARTINS, V. A. A adoção de gerenciamento de portfólio como uma alternativa gerencial: o caso de uma empresa prestadora de serviço de interconexão eletrônica. Produção, v. 15, n. 3, p. 416-433, 2005.

ROUSSEL, P.; SAAD, K. N.; ERICKSON, T. J. Third generation R\&D managing the link to corporate strategy. Cambridge: Harvard Business School Press, 1991.

SAATY, T. L. Método de análise hierárquica. São Paulo: Ed. Makron Books do Brasil, 1991.

SAATY, T. L. The seven pillars of the hierarchy process. In: INTERNATIONAL SYMPOSIUM ON THE ANALYTIC HIERARCHY PROCESS, 1999, Kobe. Proceedings...

SIMON, H. A. The new science of management decision. New York: Harper \& Brothers Publishers, 1960.

SLACK, N. Vantagem Competitiva: atingindo competitividade nas operações industriais. Tradução Sônia Corrêa; revisão técnica Henrique Luiz Corrêa. São Paulo: Atlas, 1993.

SLACK, N. Generic trade-offs and responses: an operations strategy analysis. International Journal of Business Performance Management, v. 1, n. 1, p. 13-27, 1998.

SLACK, N. et al. Administração da Produção. São Paulo: Atlas, 1999.

THIOLLENT, M. Metodologia da pesquisa-ação. 13 ed. São Paulo: Cortez, 2004. (Coleção Temas básicos da pesquisa-ação)

TRITLE, G. L.; SCRIVEN, F. V.; FUSFELD, A. R. Resolving uncertainty in R\&D portfolios. Research Technology Management, v. 43, n. 6, p. 47-55, 2000.

WHEELWRIGHT, S. C.; CLARK, K. B. Revolutionizing new product development. New York: The Free Press, 1992. 